\title{
Numerical Investigation of Propeller-Ice Interaction Effects
}

\author{
Aaqib G. Khan \\ Australian Maritime College, University of Tasmania, \\ Newnham, TAS, Australia \\ Hamburg Ship Model Basin (HSVA), Arctic Technology \\ Hamburg, Germany \\ Quentin Hisette \\ Hamburg Ship Model Basin (HSVA), Arctic Technology \\ Hamburg, Germany \\ Heinrich Streckwall \\ Hamburg Ship Model Basin (HSVA), Propeller and Cavitation \\ Hamburg, Germany \\ Pengfei Liu \\ Marine Technology, School of Engineering, Newcastle University \\ Queen Victoria Road, Newcastle upon Tyne, NE1 7RU, UK \& \\ Harbin Institute of Technology Weihai, China
}

\begin{abstract}
An innovative numerical tool has been developed to assess the effects of propeller-ice interaction on the loads acting on the propellers. The loads are calculated as the sum of the separable hydrodynamic loads, the inseparable hydrodynamic loads and the ice contact loads. The separable hydrodynamic loads are the loads acting on the propeller in ice-free water whereas the inseparable hydrodynamic loads act on the propeller due to the ice blockage effect. Both of these loads are calculated by a panel based code. The ice-contact loads, i.e. the loads originating from the physical contact between the ice particles and the propeller, have a significant contribution to the total loads acting on the propeller and are calculated using the empirical formulae. The calculated loads are transferred to a commercial Finite Element Solver that calculates the stresses and strains developed by the said loads across the propeller blades. Several interaction scenarios are modeled \& compared, and the effect of various parameters is quantified. The simulation tool is calibrated based on the results from a model test campaign in which a linear feeding device is used to guide ice floes into a rotating model propeller to be milled under controlled conditions.
\end{abstract}

KEYWORDS: Propeller-ice interaction; ice loads; ice going vessels; fluid-structure interaction; surface panel method; finite element analysis; Arctic navigation.

\section{INTRODUCTION}

With the increase in the marine traffic in the Artic regions, there is a growing demand for reliable and efficient ice going ships. An ice going vessel needs to have the additional hull strength to withstand the hull-ice interaction loads. The shape of the hull should be such that it breaks the sea ice as the ship moves through it and the material of construction should be a metal that retains its strength in freezing temperatures. Moreover, the propulsion system also needs to be robust so that 
it can withstand the ice interaction. The interaction of the propeller with ice results in the increased torque on the engine shaft and the reduced thrust on the propeller blades. The milling of the ice by the propeller leads to a significant increase in the stresses on the blades. This can lead to the propeller blade damage, or the partial or complete loss of the propeller, which in high seas is a catastrophic situation.

Therefore, HSVA is currently engaged in research to evaluate the loads on the propellers due to the ice interactions. This is done under the project ProEis. The project is funded by the German Ministry of Economics and Technology in collaboration with HSVA, DNV GL, MMG Propeller, Voith, MV Werften and Develogic. HSVA has the in-house capabilities to perform the model tests of the ice class propellers. However, a numerical simulation tool to predict the behavior of these ice class propellers in varied ice conditions is to be developed.

A numerical simulation tool called PPB (Propeller Panel-Based) based on the surface panel method was however, earlier developed by HSVA for calculating the induced velocity field and predicting the performance of the propellers in normal (ice-free) water (Streckwall, 1998). The aim is to develop the numerical simulation tool further, so that the propeller-ice interactions can be taken into account while calculating the induced velocity field and the thrust \& torque on the propellers. A communication platform is also developed in order to transfer the load data generated by the numerical simulation tool to the commercial Finite Element Solver, for the calculation of the stresses and strains.

The results obtained from the experiments carried out in the ice tank on the propeller-ice interaction are used to calibrate the numerical simulation tool so that the error between the experimental results and simulation results is minimized, making the numerical simulation tool more accurate and precise. Once the numerical simulation tool is calibrated, the influence of the various parameters like Advance Coefficient, Depth of Cut, Ice Compressive Strength, etc. on the ice loads acting on the propellers is studied. Furthermore, the finite element analysis is also carried out to calculate the stresses and strains developed on the propeller blades and validate their structural robustness.

\subsection{PRIOR ART}

To begin with, one of the earliest researches on the subject of propeller-ice interaction was done by Jagodkin (1963). In his paper, Jagodkin is mainly concerned about the determination of the torque on the propeller due to the ice loads as the presence of ice in the water offers added resistance to the propeller rotation. He considers milling of the ice as the most important interaction and neglects the axial and radial components of the ice loads. The aim here is to provide sufficient torque to the propeller so that the propeller does not stop rotating once it encounters ice and the milling of the ice is carried out smoothly.

According to Ignatjev (1964), the blade bending moment was the most important ice load on the propeller blades. For a loading case in which the ice load is assumed to be evenly distributed over $2 / 3$ of the blade span, he proposed a set of equations to evaluate the blade bending moment of the root section.

Wind (1984) similar to Ignatjev (1964) also established that the bending moment was the most important ice load on the propeller blades. However, his approach of calculations was different in the sense that he advocated that the critical loads are not due to the milling as said by Jagodkin (1963) and Ignatjev (1964) earlier, but rather they occur during the impact events. Wind assumed 
the time interval of the impact to be equal to $1 / 6$ of the propeller rotation speed which is approximately the time taken by the blade to pass over its full chord length.

Veitch (1992) divides the process of propeller-ice interaction into three stages; the first stage is the approach of the ice fragment towards the propeller; the second stage is the blockage of the flow to the propeller blades and the third stage is the actual contact between the propeller blades and the ice followed by the milling and/or crushing of the ice fragment. According to him, the theoretical methods provided by Ignatjev (1964) and Wind (1984) to calculate the bending moment were inadequate in terms of predicting the interaction loads as they did not consider the ice mechanics. The approach that Veitch followed was mostly experimental.

Jones (1997) identified the two components of the load that was experienced by the propeller; one was the direct contact force due to the penetration of the blade into the ice block, and the second was the hydrodynamic non-contact load, including both the resistance due to the ice-free water and the resistance due to the ice fragments floating in the water. The advantage of this approach over the approach of Veitch (1992) was that apart from the experimental modeling a strong theoretical analysis was done.

Soininen (1998) analyzed only the contact loads during the propeller-ice interaction and did not include the non-contact hydrodynamic loads in his model. He laid more importance on the milling load on the back side of the propeller blade as the full scale and laboratory tests indicated that the maximum loads bend the blade backwards under normal operating conditions.

Liu (2015) implemented the Unified Polar Class Rules (URI3), by the International Association of Classification Societies (IACS), to an advanced 3D unsteady panel method for the design and the optimization of the polar class propellers. It was found that for all the blade sections, the out of plane bending moment resulted in the stress that was much higher than the stress due to the inplane bending moment and the spindle torque.

Bach (2017) performed ice milling experimental studies in air at HSVA. An ice feeding device was built so that problems of the vibration during the milling of the ice can be reduced. The model tests were carried out using a podded propeller with model sea ice. However, no numerical simulation model was developed for the purpose of a theoretical analysis.

In addition to the above, the works of Okamoto (1981a, 1981b), Bose (1998), Varma (2000), Norhamo (2009), Tsarau (2016), Polić (2016), Ye (2017), and Khan (2018) were also referred.

\section{METHODOLOGY}

The first step is to select a suitable model for accurately calculating the ice loads. After the model is selected, the present numerical simulation tool PPB is used to obtain the induced velocity field and hydrodynamic load data of the propeller. The data obtained from PPB is then processed by Ice-PPB which then calculates the hydrodynamic as well as the ice loads (torque and thrust) acting on the propeller and superimposes the two results. This load data is processed and sent to the commercial finite element (FE) solver to calculate the stresses and strains.

The most suitable model was the one used by Wang J., (2007a/b). Wang identifies three types of loads acting on the propeller in contact with ice.

a. Separable Hydrodynamic Loads. These are the loads that act on the propeller due to the presence of water. They are called separable loads as they can be calculated independently 
without the presence of ice.

b. Inseparable Hydrodynamic Loads. These are the hydrodynamic loads that act on the propeller in the presence of ice, e.g. blockage and proximity effects. Since these hydrodynamic loads cannot be calculated independently in an experiment and require the presence of ice to be evaluated, therefore they are called Inseparable Hydrodynamic Loads.

c. Ice-Milling Loads. These are the loads that act on the propeller due to the milling of ice particles by the propeller blades. They are primarily of two types; loads due to the crushing of the ice and loads due to the shearing of ice by the propeller blades.

In order to compare and calibrate these loads individually, three separate experiments were performed. In the first experiment the separable hydrodynamic loads were calculated by performing the experiment in ice-free water. In the second experiment, the ice-milling loads were calculated by performing the milling of ice by the propeller in air. Finally, in the third experiment, the total loads were calculated by performing the milling of ice by the propeller in water. Thus, by adding the load values obtained from the first and second experiment and subtracting this sum from the load values obtained from third experiment, the inseparable hydrodynamic loads were evaluated. The numerical code provides the values of all the three types of loads and thus comparison is made with respect to each type of load, as this leads to a better calibration.

\subsection{SIMULATION SOFTWARE}

The numerical simulation tool consists of several modules that help it to calculate the loads on the propellers during their interaction with ice. The Input Data Module receives the input data, like the advance coefficient, propeller diameter, etc. and sends this data to the Floe Module that processes it and sends it to Hydro Module for calculating the hydrodynamic loads (both separable and inseparable) on the propeller with the help of existing tool PPB. The Floe Module contains the detection algorithm that detects the leading edge and suction surface panels in contact with ice at a given RPM and depth of cut. This data is then sent to the Ice Module that calculates the ice loads on the propeller. The Ice Module calculates the ice loads separately and also in combination with the hydrodynamic loads to yield the total loads acting on the propeller.

\subsubsection{Propeller Geometry}

The propeller used in the present study is an ice-class propeller. It is essentially a controllable pitch podded propeller and its geometrical characteristics are listed in Table 1. A schematic representation of the same is shown in Fig 1 . The model used for the experiments had a scale factor of 21.

Table 1: Geometrical Characteristics of the Propeller

\begin{tabular}{|ll|l|l|}
\hline Parameter & Full Scale & Model Scale \\
\hline Diameter & {$[\mathrm{mm}]$} & 4200 & 200 \\
Hub Diameter & {$[\mathrm{mm}]$} & 1617 & 77 \\
\hline
\end{tabular}



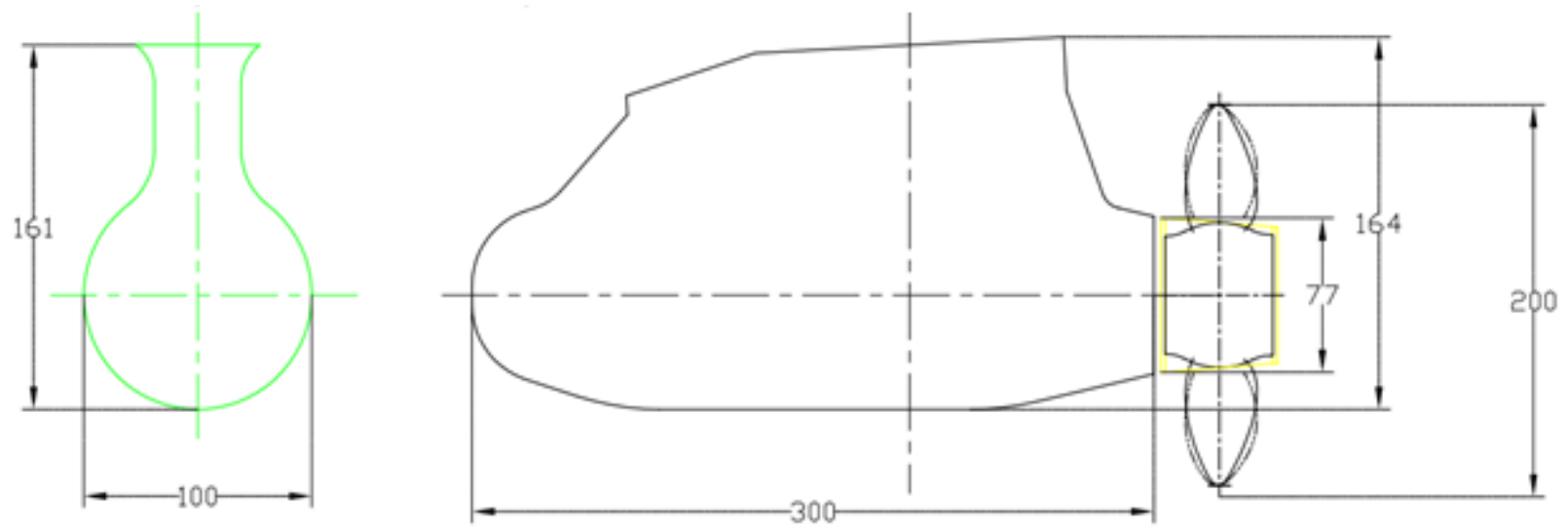

Fig 1- Schematic Representation of the Propeller

Moreover, an elliptical shaped hub cap (not shown in Fig 1) was placed on the upstream surface of the propeller hub to smoothen the flow as the hub of this propeller is considerably large as compared to its diameter.

\subsubsection{Simulation Set-up}

The numerical simulation tool has been developed in order to calculate the loads on the propeller in two different conditions, called the planar mode and the sector mode. In the planar mode (Fig 2), a planar sheet of ice is encountered by the propeller. This is usually the standard practice when experiments are performed on propeller-ice interaction, as it provides a very controllable and highly repeatable configuration. However, in real scenarios, ice particles can interact at different locations of the propeller disc. This kind of situation is also simulated by the numerical tool by using the sector floe mode, in which an ice particle comes in contact with the propeller in a certain region (or sector) of the propeller disc as shown in Fig 3.

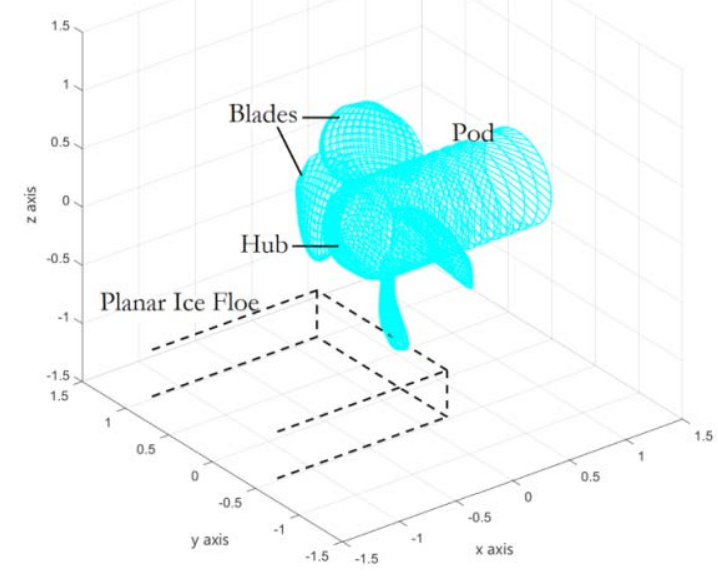

Fig 2 - Propeller Interacting With a Planar Ice Floe

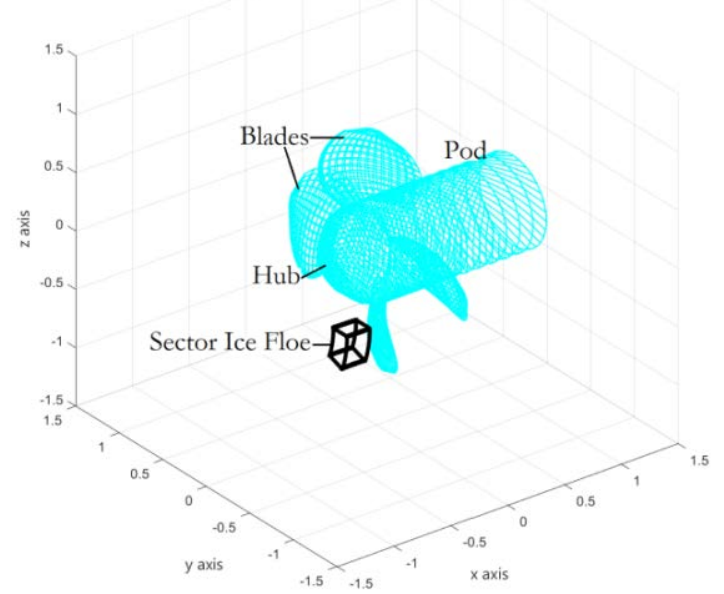

Fig 3 - Propeller Interacting with a Sector Ice Floe 


\subsubsection{Hydrodynamic Loads}

The hydrodynamic loads consist of the separable and inseparable hydrodynamic loads. The separable hydrodynamic loads are synonymous to the open water loads and are therefore calculated in a similar fashion. The inseparable hydrodynamic loads come into play due to the blockage effect of the incoming ice floes. This blockage effect of the ice floes is modeled by a wake field. The modelling of the ice wake field consists of two parts; the first part is the determination of the velocity of water in the wake region and second part is the determination of the region around the propeller disc in which the wake effect will be observed.

Wake Velocity: The movement of the ice floes towards the propeller can be described in three stages as shown in Fig 4. During the approach phase, the ice floe gets into the propeller race and starts its motion towards the propeller disc. In the propeller race, due to the acceleration of the fluid, the relative axial velocity between the ice floe and the propeller increases leading to disruption of the fluid flow, producing an ice wake. During the blockage phase, the ice floe is in the immediate vicinity of the propeller and the ice wake effect reaches its maximum. The ice wake $\left(V_{W}\right)$ is almost equal to the ship speed $\left(V_{S}\right)$ and as a result the velocity of the fluid entering the propeller or the advance velocity $\left(V_{A}=V_{S}-V_{W}\right)$ is essentially zero, making the flow stagnant. This leads to the increase in the hydrodynamic loads on the propeller, the origin of the so-called inseparable hydrodynamic loads. However, according to Bose (1996), the advance velocity is not zero, but $\approx 0.01$ times the ship speed.

Wake Region: The determination of the wake region is done in two different ways for the planar and sector ice floe.

For planar ice floes (which are generally used in experiments), the wake region changes with the depth of cut and the radius of the propeller. The wake region is essentially a sector having an angle equal to the milling angle $\left(\alpha_{m}\right)$, the outer radius is the radius of the propeller and the inner radius is the difference between the propeller radius and the depth of cut as shown in Fig 5.

The wake region for a sector ice floe is quite simple to calculate as the wake is in the same region as that of the ice floe itself, whose geometry is characterized by its inner and outer radii and its delimiting angles. The influence of the ice wake on the advance velocity for the planar and sector ice floes can be seen in Fig 6 and Fig 7 respectively. The values of normalized advance velocity are plotted around the propeller disc and they show a significant decrease in and around the wake region. 


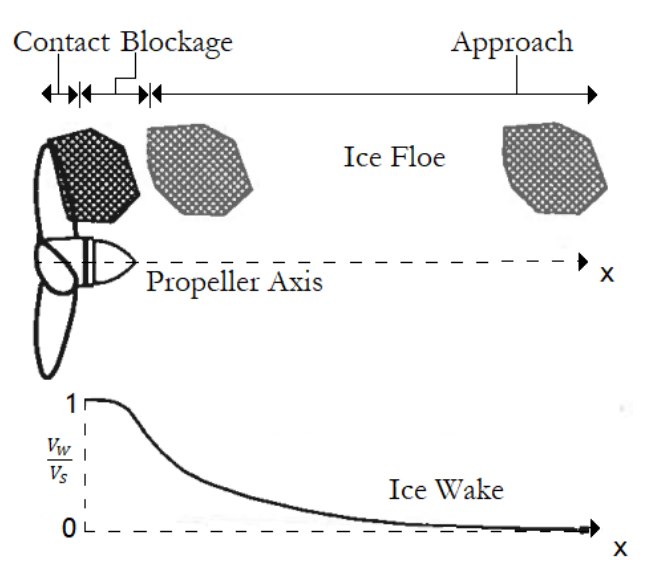

Fig 4 - Three Stages of Propeller Ice Interaction (modified from Veitch, 1995)

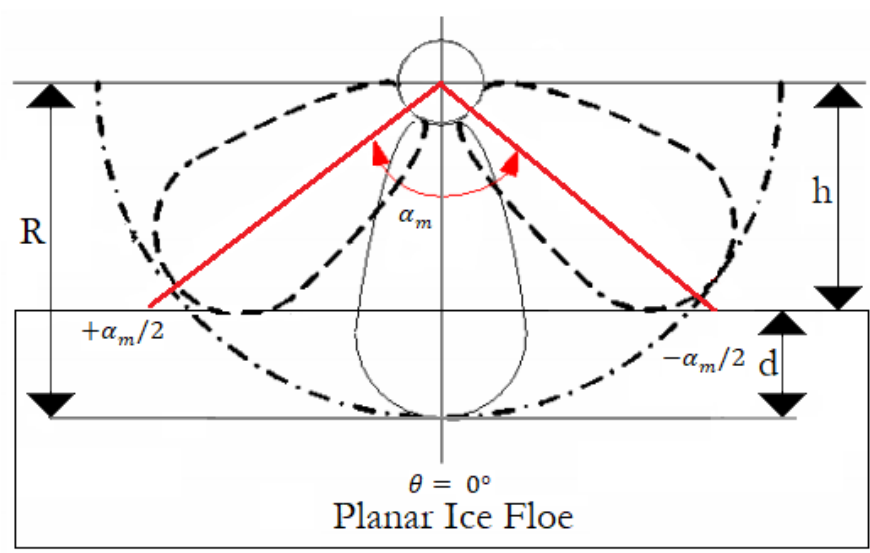

Fig 5- Determination of the Milling Angle for a Planar Floe

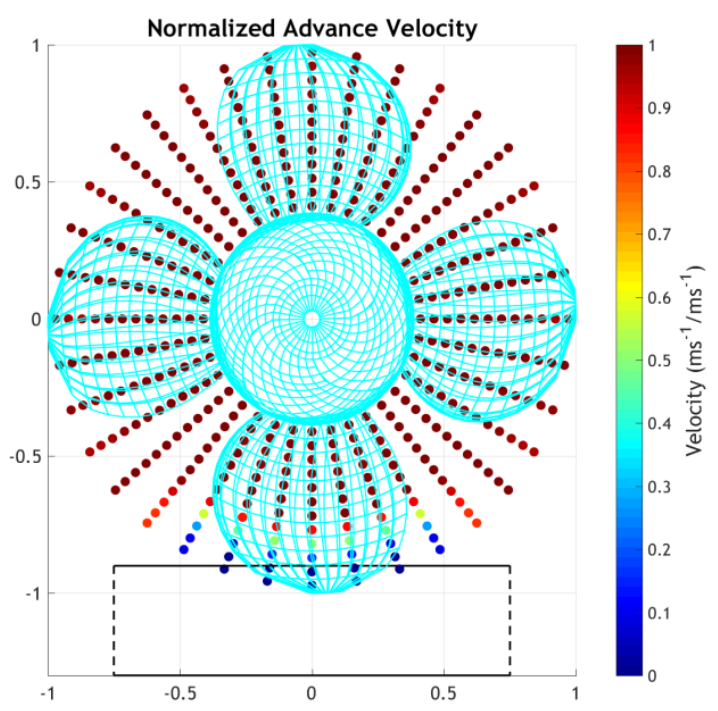

Fig 6- Distribution of the Normalized Advance Velocity around the Propeller Disk in Case of Interaction with a Planar Ice Floe (black)

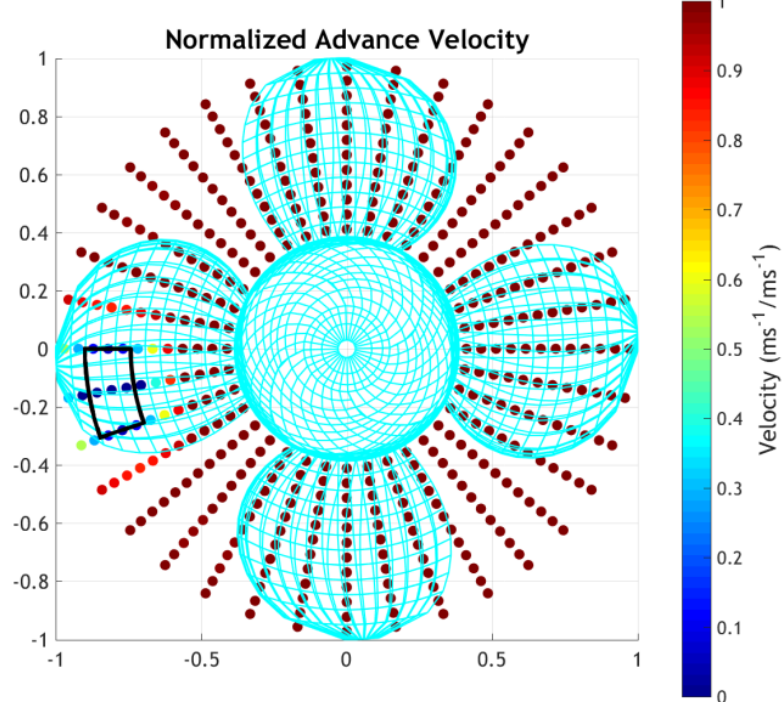

Fig 7- Distribution of the Normalized Advance Velocity around the Propeller Disk in Case of Interaction with a Sector Ice Floe (black)

Calculation of Hydrodynamic Loads: The hydrodynamic loads (separable and inseparable) are calculated with the help of PPB, a panel based code. The PPB does not directly calculate the hydrodynamic thrust force and torque on the propeller, rather it provides the values of normal and tangential forces acting on each panel. These forces are normalized to obtain the coefficient of pressure $\left(C_{p}\right)$ and normalized tangential force per unit area $\left(T_{w}\right)$ using the formulae shown in equation (1a).

$$
C_{p}=\frac{F_{\text {normal }}}{\frac{1}{2} \rho a(\omega R)^{2}}, \quad T_{w}=\frac{F_{\text {tangential }}}{\frac{1}{2} \rho a(\omega R)^{2}}
$$

Where, $\rho$ is the density of water, $a$ is the panel area, $\omega$ is the angular frequency of the propeller and $R$ is the radius of the propeller. The reason for such normalization is that it makes the 
calculation of the thrust coefficient $\left(K_{T}\right)$ and the torque coefficient $\left(K_{Q}\right)$ much simpler in the later part of the code.

The values of $C_{p}$ and $T_{w}$ are calculated for each panel of the propeller. Using the values of normal and tangential vectors of each panel, the 3 components of the force $\left(f_{x}, f_{y}\right.$ and $\left.f_{z}\right)$ acting on each panel of the propeller is determined. The force $f_{x}$ acts along the $x$ direction and directly contributes to the thrust produced by the propeller. The forces $f_{y}$ and $f_{z}$ generate moments about the propeller axis and this moment directly contributes to the torque generated on the propeller shaft.

The force $f_{x}$ on each panel is added to obtain the thrust on the propeller and the moment generated by each panel due to the forces $f_{y}$ and $f_{z}$ is added to obtain the torque generated on the propeller shaft. Once, the thrust $(T)$ and torque $(Q)$ are obtained, the thrust coefficient $\left(K_{T}\right)$, the torque coefficient $\left(K_{Q}\right)$ and the efficiency $(\eta)$ are obtained using,

$$
J=\frac{V}{n D}, \quad K_{T}=\frac{T}{\rho n^{2} D^{4}}, \quad K_{Q}=\frac{Q}{\rho n^{2} D^{5}}, \quad \eta=\frac{J}{2 \pi} \frac{K_{T}}{K_{Q}}
$$

Where, $V$ is the advance velocity, $n$ is the propeller revolution rate, $D$ is the propeller diameter and $\rho$ is the water density.

\subsubsection{Ice Contact Loads}

The ice milling loads are divided into crushing and shearing loads and two different empirical formulae are used by Wang (2007a/b) to calculate these loads.

The crushing of ice takes place when the leading edge of the propeller blades comes in the contact with the ice floe and breaks the top granular layer of the ice. This type of contact can be seen in Fig 8 (left) as shown below. The shearing of the ice takes place when the leading edge slices a thin layer from the front surface of the ice floe (i.e., the surface parallel to the propeller disc plane) as shown in Fig 8 (right). Furthermore, in one blade pass from the start of milling to the end of milling, the crushing takes place for a brief moment when the leading edge hits the top granular layer of ice. Afterwards, the shearing takes place for the remaining duration of milling.

Fig 8 is a snapshot from a high-speed camera and it shows the difference in the two types of processes that take place during ice milling. The ice loads mainly act on the leading edge panels and on the panels located on the upstream of the propeller disc, also called the suction panels. 


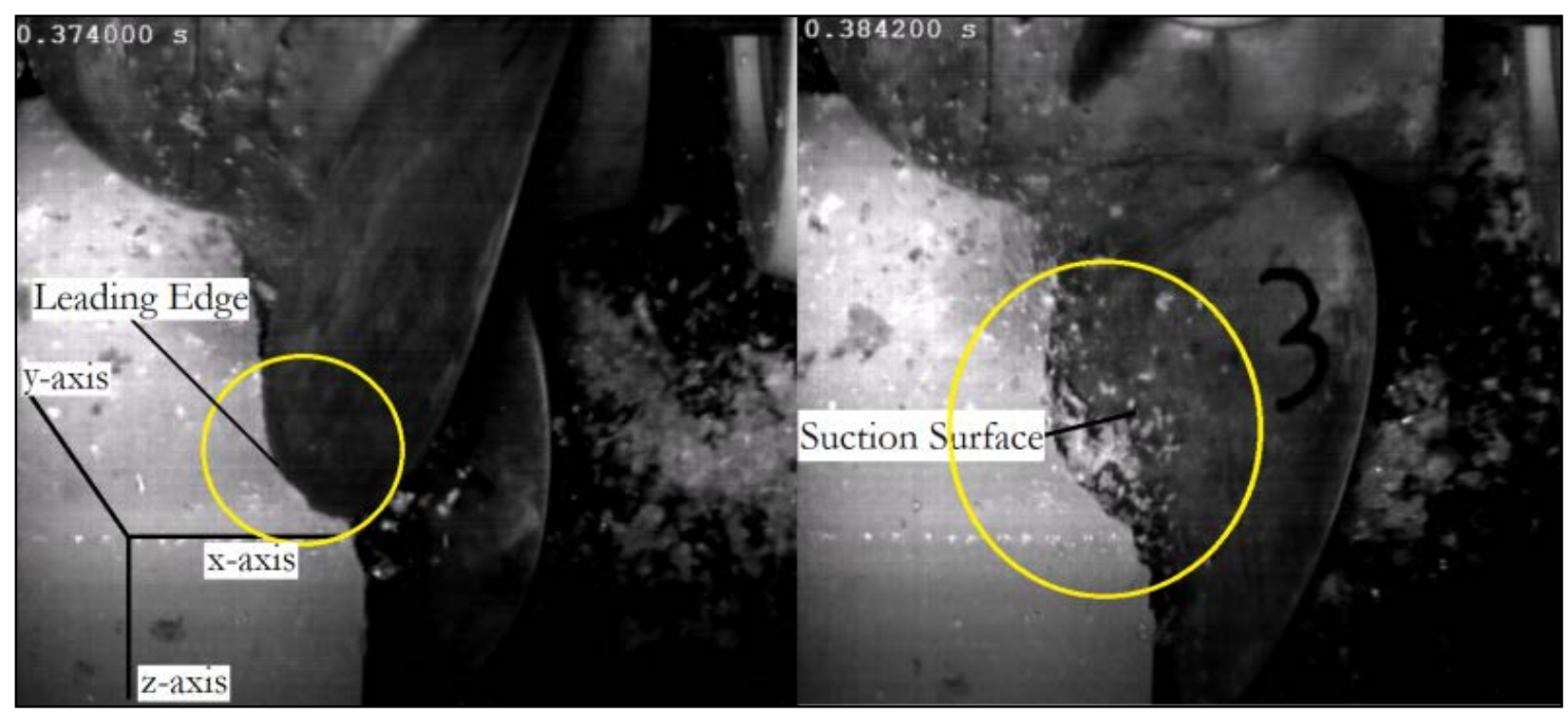

Fig 8 - Crushing (left) and Shearing (right) of Ice during Milling

Wang (2007a/b) developed separate empirical formulae for the crushing and shearing of ice and used separate empirical factors in each case. The pressure on each panel is given as,

$$
\begin{gathered}
P_{\text {crushing }}=w \cdot E F C \cdot S_{\text {ice }} \\
P_{\text {shearing }}=S_{\text {ice }} / E F S
\end{gathered}
$$

As mentioned above, the hydrodynamic code (PPB) calculates the normalized coefficients $C_{p}$ and $T_{w}$ (equation (1a)) on each panel and in order to maintain conformity in the calculations, the values of the pressures in equation (2) and (3) are similarly normalized as equation (1a) to obtain $C_{p}$ and $T_{w}$ due to ice loads as shown in equations (4) and (5). Note that in equations (4) and (5), we do not have panel area $a$, this is due to the fact that we are normalizing pressures and not forces in these equations.

$$
\begin{array}{r}
C_{p}=\frac{P_{\text {crushing }}}{\frac{1}{2} \rho(\omega R)^{2}} \\
T_{w}=\frac{P_{\text {shearing }}}{\frac{1}{2} \rho(\omega R)^{2}}
\end{array}
$$

Where, $S_{\text {ice }}$ is the ice compressive strength, $w$ is the weighing factor, EFC is the Empirical Factor for Crushing, EFS is the Empirical Factor for Shearing, $\omega$ is the propeller angular frequency and $R$ is the radius of the propeller. The $C_{p}$ and $T_{w}$ values calculated in the equations (4) and (5) are then added to the panels of the propeller that are affected due to ice milling in order to calculate the ice loads.

The empirical weighing factor $(w)$ has an average or base value of 1 and a maximum value of 6 (Wang, 2007a/b). The maximum value is used to calculate the pressure on the leading edge panels, 
which undergo severe impact loading during the milling of ice. The average value of 1 is used to calculate the pressure on the suction panels which have a considerable small loading during the ice milling. The values of EFC and EFS are determined from the experimental data using the equations (8) - (10), shown below in section 2.2.3 (Calibration of Ice Contact Loads).

Moreover, not all the suction panels present in the ice field (region of the propeller disc in which ice is present) come in contact with the ice floe as the front face (y-z plane) of the floe is not parallel to the suction surface of the blades due to the non-zero pitch angle. As a result, as the ice floe moves towards the rotating blades of the propeller, different parts of the suction surface come in contact with the floe at different blade positions. In order to correctly simulate this effect, a detection algorithm was developed that determines the suctions side panels in contact with the floe at a given instant. This effect is termed as the shadow effect (some parts of the blade shadow out other parts and prevent them from contacting the ice floe) and the suction panels in contact with the ice floe are called shadow panels. The algorithm for the detection of the shadow panels is explained in the next section. However, the inherent assumption here is that the ice floe is strong enough to survive the first blade impact and is not shattered into smaller pieces that are then no longer involved in the ice-milling process.

\subsubsection{Shadow Effect}

Due to the non-zero pitch angle of the propeller, some parts of the blade are closer to the ice floe than the others. The leading edge of the blade is closest to the ice floe and the trailing edge is the farthest. The leading edge comes in contact with the floe first and hits it at an oblique angle as seen from the high speed footage (Fig 8). As the leading edge moves away, the suction surface then moves in front of the ice floe, some parts of the surface (ones towards the leading edge) being closer to the ice floe than the remaining parts. However, at the same time the ice floe also moves forward towards the propeller.

The propeller blades are rotating at a frequency of $n(\mathrm{~Hz})$ and the ice floe is moving towards the propeller at a velocity of $V(\mathrm{~m} / \mathrm{s})$. In a given time interval $\Delta t$, the ice floe advances by a distance (d) towards the propeller and in the same time interval $\Delta t$, the blade of the propeller turns by an angle $(\theta)$. Thus,

$$
J=\frac{V}{n D}, \quad d=J n D \Delta t, \quad \theta=2 \pi n \Delta t
$$

Now, for a propeller with $b$ number of symmetric blades, the angle traversed in one blade rotation $(\theta)$ is given as,

$$
\theta=\frac{2 \pi}{b}, \quad \Delta t=\frac{2 \pi}{2 \pi n b}, \quad d=\operatorname{Jn} D \frac{2 \pi}{2 \pi n b}=\frac{J D}{b}
$$

Therefore, a suction panel at a particular radius $(r)$ in the ice field will come in contact with the ice floe only when the sum of the x-coordinate of any one out of four points of the leading edge panel at the same radius $(r)$, and the distance travelled by the ice-floe $(d)$ is greater or equal to the $\mathrm{x}$-coordinate of the any one out of four points of the suction panel. When this condition is met by a panel, it will come in contact with the ice flow and become a shadow panel. Thus, the number of suctions panels at a given depth of cut (DOC) depends on the propeller geometry $(b, D)$ and the advance coefficient $(J)$. The variation of shadow panels (in black) with the advance coefficient is 
shown in Fig 9 below.

For a given depth of cut (DOC), the number of shadow panels increases with the increase in the value of $\mathrm{J}$. However, after a particular value of $\mathrm{J}$ all the shadow panels are selected and there is no further increase in the number of shadow panels with the increase in value of J. This value is called the critical $\mathrm{J}$ value and is equal to 0.7 for the example shown in Fig 9.

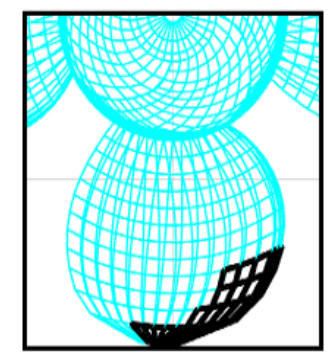

$\mathrm{J}=0.1$

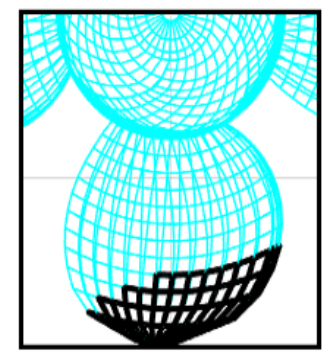

$\mathrm{J}=0.4$

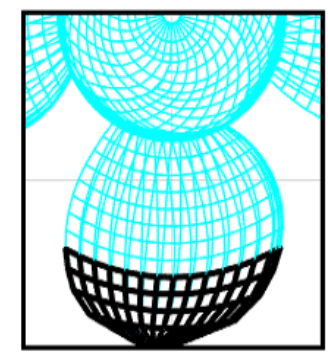

$\mathrm{J}=0.7$

Fig 9 - Variation of the Shadow Panels with Advance Coefficient at a given DOC

\subsubsection{Panel Size Resolution}

Since, the numerical simulation tool is based on the panel method, the size of the panels plays an important role in the accuracy of the results. A convergence study therefore needs to be performed beforehand in order to determine the optimum panel size. The panel size near the leading edge (LE) must be relatively small and the size increases from leading edge to trailing edge.

A coarse mesh can introduce uncertainty in the results especially in the case of LE panels, because the smooth transition of curvature becomes difficult to define, and the numerical tool may select too many or too less panels as LE panels. Furthermore, since the empirical weighing factor $(w)$ of 6 is applied on these panels, it will greatly skew the results.

Furthermore, the blade tip also has a finer mesh as the curvature change has a steep gradient here. A finer mesh ensures the smooth selection of the shadow panel in this region. This region is critical as it plays a major role in ice milling.

\subsection{EXPERIMENTAL VALIDATION}

Three types of experiments were performed to calibrate the code with respect to the three types of loads. The separable hydrodynamic loads calculated with the code were compared with the experimental results from an open water test. For the ice loads, the results from the code were compared with the experimental results from the air milling of ice and finally, for the inseparable hydrodynamic loads the code was calibrated by comparing the results from the water milling, air milling and the open water test.

\subsubsection{Separable Hydrodynamic Loads}

A comparison between the results of the numerical code and the experiment for the open water test are shown in Fig 10. Since, the hydrodynamic loads are calculated using a panel method based on potential theory, the effect of viscosity is to be taken into account. In order to match the results of the numerical code with the experiments, a mathematical correction for viscosity was done. This 
mathematical correction helps in modelling the flow separation at high angles of attack at low values of $\mathrm{J}$. It is done in addition to the simple flat plate viscous correction already present in PPB (Streckwall, 1998).

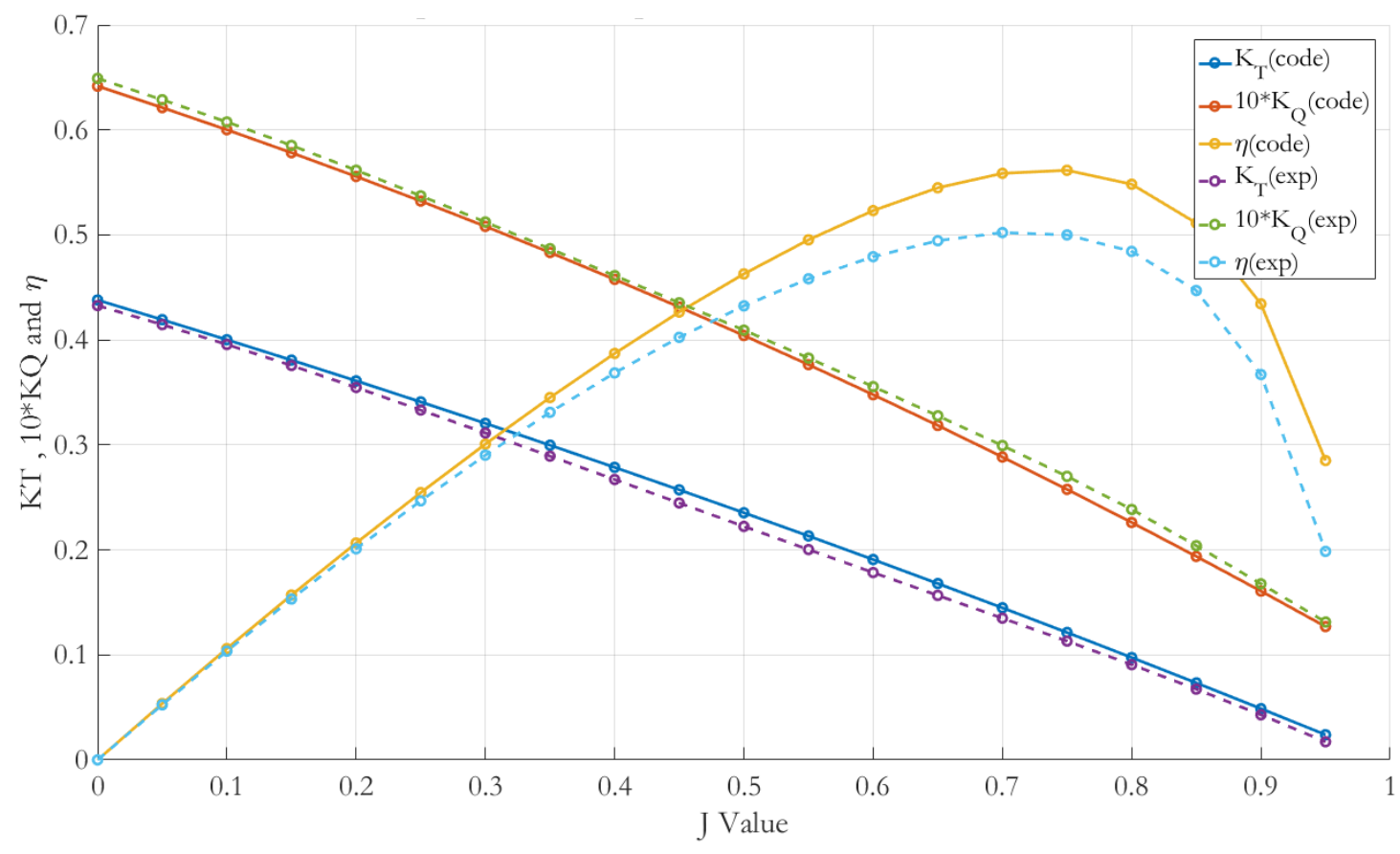

Fig 10 - Comparison of the Open Water Results after calibration of the simulation tool

\subsubsection{Inseparable Hydrodynamic Loads and Ice Contact Loads}

The ice milling experiments in air and water were carried out in the large ice tank of HSVA. The two experiments are similar in every sense except that the surrounding medium is different. These experiments, along with the open water experiment, are used to calibrate the inseparable hydrodynamic loads and the ice contact loads.

Experimental Set-up: The apparatus used for the milling experiments is shown in Fig 11. This socalled Ice Feeding Device has been developed at HSVA on the basis of preliminary concept designed by Bach (2017). It consists of a linear ice feeding mechanism (B) that allows the feeding of the ice probes (D) into a rotating model podded propeller (C). The clutches fitted on a fixed structure allow to secure the ice feeding device in two positions, one for testing in air and loading the ice probes, and another one for testing underwater (Fig 11, below). 

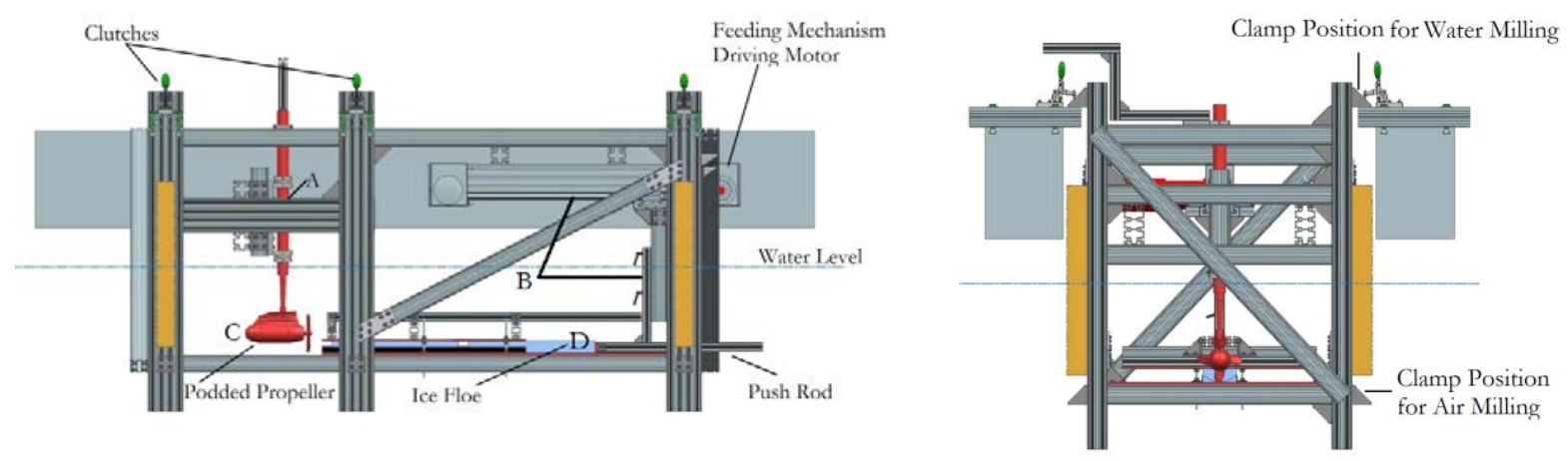

Fig 11 - Side (Right) and Front (Left) Views of the Ice Feeding Device

The propeller pod houses the load cells to measure the torque and thrust acting on the propeller. The actual test set-up slightly differed from Fig 11, as a 6 component dynamometer was mounted instead of a simple clamping system (A), so that total forces and moments acting on the pod along $\mathrm{x}, \mathrm{y}$ and $\mathrm{z}$ axis could be measured as well. Further calibration tests are intended to be performed in the future with an instrumented propeller hub, allowing measuring forces and moments at the root of the blades. Measurement system is also expected to be improved, resulting in significantly less noise in the raw data signals.

For the current calibration phase, four ice milling tests were carried out. The test scope included two tests in air and two tests underwater (Table 2). The two feeding speeds have been tested, corresponding to advance coefficients of 0.015 and 0.045 .

Table 2: Experimental Test Parameters

\begin{tabular}{|c|c|c|c|c|c|}
\hline Test No. & & $\# 1$ & $\# 2$ & \#3 & \#4 \\
\hline Testing Medium & & Air & Air & Water & Water \\
\hline Ice Feeding Speed & {$[\mathrm{mm} / \mathrm{s}]$} & 27 & 81 & 27 & 81 \\
\hline Propeller RPS & {$[1 / \mathrm{s}]$} & 9 & 9 & 9 & 9 \\
\hline Advance Ratio & {$[-]$} & 0.015 & 0.045 & 0.015 & 0.045 \\
\hline Depth of cut & {$[\mathrm{mm}]$} & 17 & 17 & 27 & 27 \\
\hline Ice Compressive Strength & {$[\mathrm{MPa}]$} & 1.41 & 1.41 & 1.03 & 1.03 \\
\hline
\end{tabular}

\subsubsection{Data Processing}

The data recorded by the measurement system, called the raw data, exhibited significant noise due to vibrations during ice milling, wobbling of the propeller axis, unbalanced propeller blades, etc. The typical measurement signals from one of the tests are shown in Fig 12. In order to get the useful information from the raw data, a series of data processing techniques were employed as mentioned below. The data processing was carried out using the Signal Processing Toolbox of MATLAB.

a) Offset Correction: From Fig 12 we can see that for the air milling test run, the propeller is running idle for some time before the milling commences, which is marked by the sudden peak 
in the torque and thrust values. Since the propeller is running in idle condition in air, there should be no loads acting on it. However, if we look at Fig 12, we can see that both the thrust and torque data have a non-zero average value during this time period. This can be due many reasons, like offset in the sensor, or an unbalanced force in the system due to vibrations, etc. As a result, this offset must be removed first before proceeding for further signal processing. This process is known as the offset correction. The offset value is calculated as the difference between the average of the data before milling and zero value. This offset value is then added to the whole signal as shown in Fig 13.
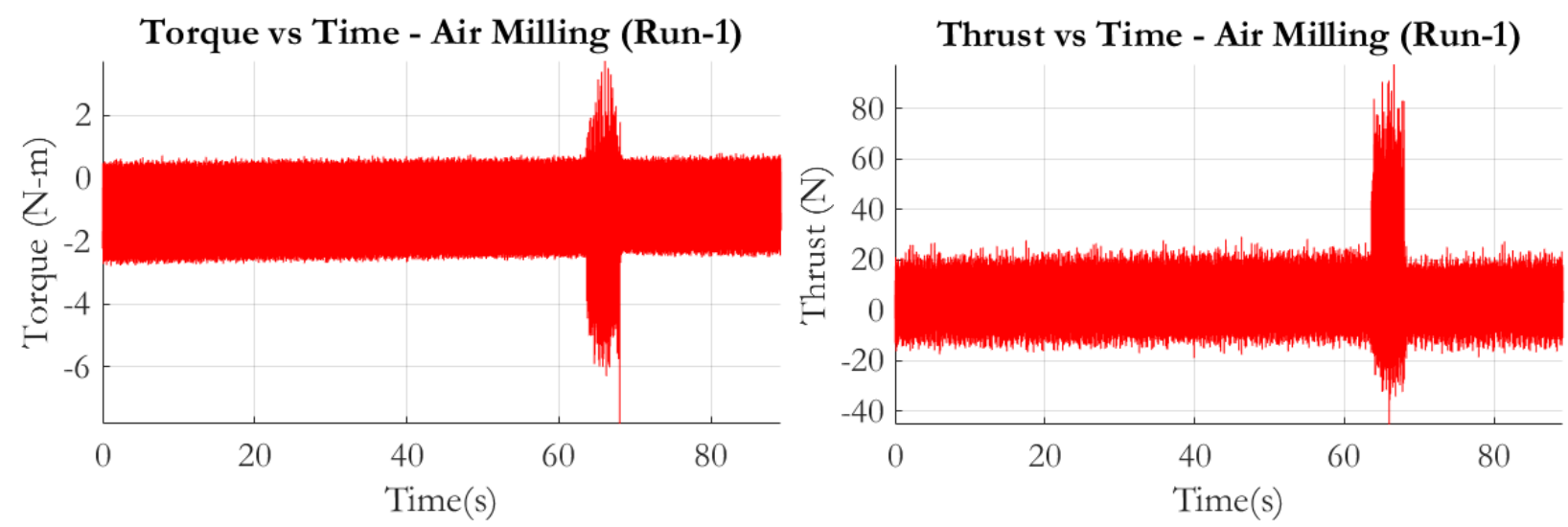

Fig 12 - Example of Measured Torque and Thrust Signals (Test \#1)

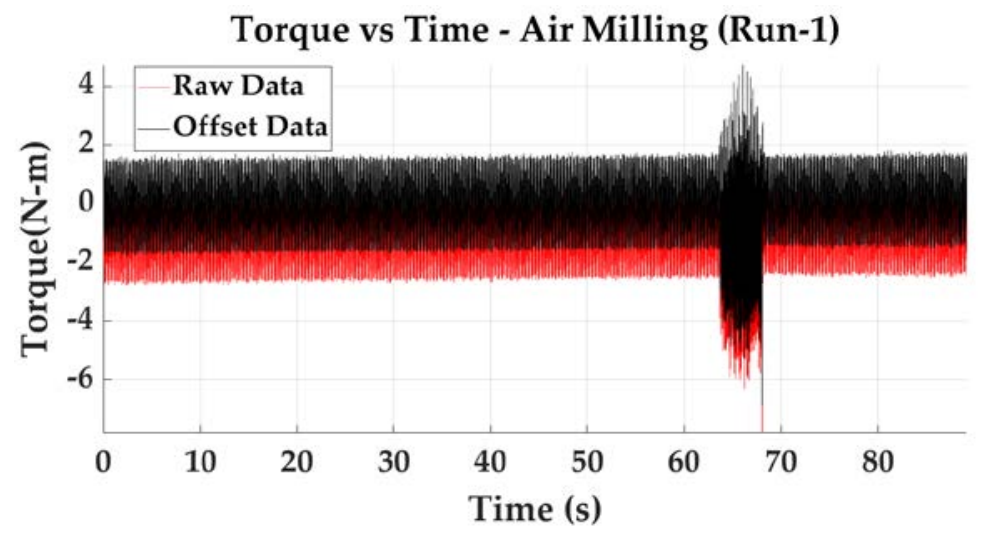

Fig 13 - Comparison of Raw Data and Offset Data for Torque Signal (Test \#1)

b) Frequency Filter: After applying the offset correction to the raw data, the noise was filtered out using a frequency filter so that the data at a given frequency and its harmonics was retained, and the remaining data was eliminated as noise. In the present experiment, the propeller was rotating at a frequency of $9 \mathrm{~Hz}$ and therefore, a significant amount of the relevant data was recorded in the raw signal at this frequency. Additionally, the propeller had 4 blades, so that another frequency filter was required to be added at $36 \mathrm{~Hz}$. A Fourier Transform analysis revealed that ice milling data was present even up to the $25^{\text {th }}$ harmonic $(225 \mathrm{~Hz})$ of the propeller frequency $(9 \mathrm{~Hz})$. The design parameters of the frequency filter used are shown in Table 3 below. Fig 14a shows the comparison between the filtered and raw data after offset correction. The Fig 14b shows four thrust peaks (corresponding to the four blades) per one 
revolution of the propeller at $9 \mathrm{~Hz}$. The peaks cane be seen occruing at a time interval of $\sim 0.026 \mathrm{~s}$ which corresponds to the frequency of $\sim 36 \mathrm{~Hz}$.
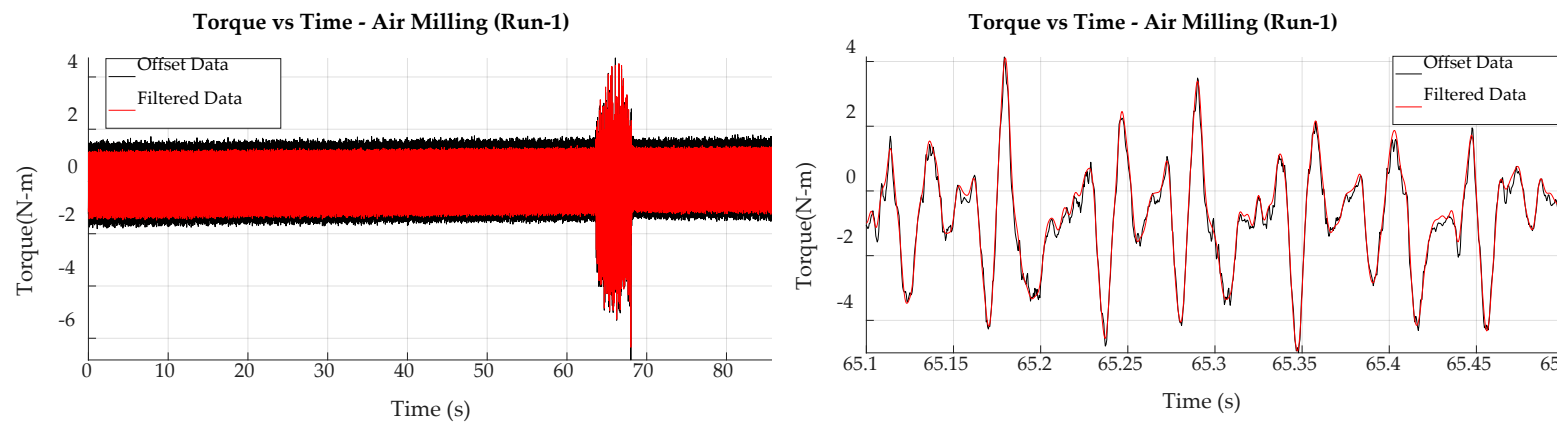

Fig 14a - Comparison of Offset Data and Filtered Data (left). Zoomed over the milling event (right). Thrust vs Time - Air Milling (Run-1)

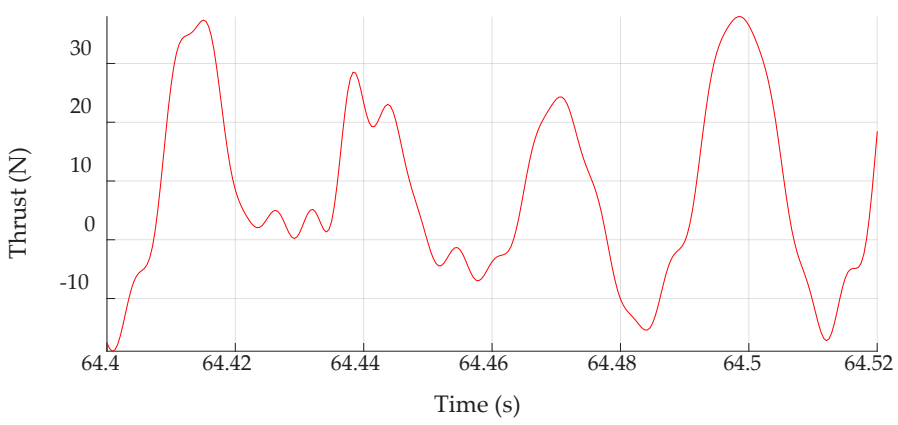

Fig 14b - Four thrust peaks corresponding to the four propeller blades during a milling event.

Table 3: Design Parameters of the Frequency Filter

\begin{tabular}{|l|l|}
\hline Parameter & Value \\
\hline Impulse Response & Infinite \\
Design Algorithm & Chebyshev Filter, Type II \\
Filter Technique & Band-pass \\
Filter Order & 20 \\
Sampling Frequency & $2400 \mathrm{~Hz}$ \\
Primary Frequency & $9 \mathrm{~Hz}$ \\
Number of Harmonics & 25 \\
Pass band Frequencies & 9 to 225 \\
Pass band attenuation & $60 \mathrm{~dB}$ \\
\hline
\end{tabular}

Additionally, for each of the ice floes used in the 4 tests mentioned above, the ice compressive strength was determined by testing the samples on a compression testing machine (Table 2). 
Calibration of Ice Contact Loads: In order to calibrate the numerical code for the ice contact loads, the experimental data is used to calculate the Empirical Factor for Crushing (EFC) and Shearing $(E F S)$. The $E F C$ is estimated to be equal to the ratio of the compressive strength of ice floe (in $\mathrm{MPa}$ ) and the strain rate developed in the ice floe during milling. The calculation of the strain rate at high indentation speeds is quite difficult as the change in the length cannot be determined accurately due to the brittle nature of the ice. In order to overcome this limitation, an empirical formula developed by Cammaert (1988) was used to calculate the strain rate as,

$$
\begin{gathered}
\dot{\varepsilon}=\frac{V}{4 D}=\frac{2 \pi R n}{4(2 R)}=\frac{\pi n}{4} \\
E F C=\text { Ice Compressive Strength }(M P a) / \text { Strain Rate }
\end{gathered}
$$

Where $V$ is the indentation speed, $n$ is the propeller RPS, $R$ is the propeller radius, and $D$ is the propeller diameter. Using the experimental data from Table 2, the value of EFC was calculated as 0.2 for the air milling and 0.145 for the underwater milling. The EFS is defined as the ratio of the compressive strength and shear strength of the ice floe across a given cross section. Since, no ice shear test could be done by the authors, therefore, based on the multiple previous testing of HSVA model ice, an average of 4.27 was selected for this ratio. This value is similar to the one used by Wang (2007a/b) in his numerical model (4.00).

$$
E F S=\frac{\text { Ice Compressive Strength }(\mathrm{MPa})}{\text { Ice Shear Strength }(\mathrm{MPa})}
$$

After assigning the values to the empirical factors, the results were obtained using the numerical code Ice-PPB and a comparison was made with the experimental results (Table 4). For comparing the results of the air milling, the numerical code calculates only the ice loads and deletes the hydrodynamic loads and for the water milling, it adds up the hydrodynamic loads (separable and inseparable) and the ice loads. The errors are between $\pm 15 \%$ which are within the acceptable limits. For the experiments involving ice loads, HSVA considers errors up-to $\pm 20 \%$ as acceptable based on their expertise on the subject matter which is a consequence of many research and commercial projects.

Table 4: Comparison of results from Code and Experimental Tests

\begin{tabular}{|l|l|l|l|l|l|l|}
\hline Test No. & $\mathrm{K}_{\mathrm{T}}$ exp. & $\mathrm{K}_{\mathrm{T}}$ code & Error in $\mathrm{K}_{\mathrm{T}}$ & $10 * \mathrm{~K}_{\mathrm{Q}}$ exp. & $\begin{array}{l}10 * \mathrm{~K}_{\mathrm{Q}} \\
\text { code }\end{array}$ & $\begin{array}{l}\text { Error in } \\
10 * \mathrm{~K}_{\mathrm{Q}}\end{array}$ \\
\hline$\# 1$ & -0.1326 & -0.1208 & $9.7 \%$ & 0.7027 & 0.7836 & $-10.3 \%$ \\
$\# 2$ & -0.2651 & -0.2419 & $9.6 \%$ & 1.0560 & 1.2143 & $-13.0 \%$ \\
$\# 3$ & 0.3126 & 0.3689 & $-15.3 \%$ & 1.7239 & 1.5548 & $10.9 \%$ \\
\hline 4 & 0.2010 & 0.2105 & $-4.5 \%$ & 2.3870 & 2.2634 & $5.5 \%$ \\
\hline
\end{tabular}

The Table 4 only compares the values of the final output from the Code and in order to ensure that there are no errors in the calculation that tend to cancel out each other's influence, a comparison of intermediate quantities was also performed. Table 5 below shows the comparison between the forces in $\mathrm{x}$ and $\mathrm{y}$ direction from the Code and the Experimental Tests. The force in $\mathrm{z}$ direction could not be compared as it was not recorded during the experiment. 
Table 5: Comparison of forces from Code and Experimental Tests

\begin{tabular}{|l|l|l|l|l|l|l|}
\hline Test No. & $\begin{array}{l}\mathrm{F}_{\mathrm{x}} \text { exp. } \\
{[\mathrm{N}]}\end{array}$ & $\begin{array}{l}\mathrm{F}_{\mathrm{x}} \text { code } \\
{[\mathrm{N}]}\end{array}$ & Error in $\mathrm{F}_{\mathrm{x}}$ & $\begin{array}{l}\mathrm{F}_{\mathrm{y}} \text { exp. } \\
{[\mathrm{N}]}\end{array}$ & $\begin{array}{l}\mathrm{F}_{\mathrm{y}} \text { code } \\
{[\mathrm{N}]}\end{array}$ & $\begin{array}{l}\text { Error in } \\
\mathrm{F}_{\mathrm{y}}\end{array}$ \\
\hline$\# 1$ & -17.35 & -15.66 & $10.8 \%$ & 8.81 & 9.17 & $-3.9 \%$ \\
$\# 2$ & -34.76 & -31.35 & $10.9 \%$ & 14.22 & 15.18 & $-6.3 \%$ \\
$\# 3$ & 55.51 & 47.81 & $-16.1 \%$ & 21.12 & 19.51 & $8.3 \%$ \\
$\# 4$ & 28.75 & 27.28 & $-5.4 \%$ & 33.31 & 32.11 & $3.6 \%$ \\
\hline
\end{tabular}

Since, the force in $\mathrm{x}$ direction is a direct measure of the thrust coefficient (equation (1b)), it is expected that the error values of $F_{x}$ show a similar trend as that of the $K_{T}$ values. From Table 4 and Table 5 it can be seen that although the errors follow a similar trend, the errors values of $F_{x}$ are slightly higher ( 0.8-1.3\%). This can be attributed to the fact that two different sensors were used to measure thrust (from which $K_{T}$ values were calculated in Table 4 ) and $F_{x}$. The thrust sensor was located in the pod of the propeller and the dynamometer was attached to the clamp system (Fig 11). Furthermore, a comparison of the $F_{y}$ values shows that the values calculated by the Code are similar to those recorded by the dynamometer during the experiment as the errors are within acceptable limits.

Calibration of Inseparable Hydrodynamic Loads: The open water and the air milling experiments (Tests \#1 and \#2) are used to calibrate the separable hydrodynamic loads and ice contact loads respectively. From the results obtained from Fig 10 and Table 4, it can be seen that the difference between the results obtained from the code and experiment for the open water and ice contact loads is quite small. Furthermore, it can also be seen that the difference between the total loads obtained from the numerical code and the water milling experiment (Tests \#3 and \#4) is also small. We have,

$$
L_{I S H}=L_{T}-L_{S H}-L_{I C E}
$$

Where, $L_{I S H}$ is the inseparable hydrodynamic load, $L_{T}$ is the total load, $L_{S H}$ is the separable hydrodynamic load, and $L_{I C E}$ is the ice contact load.

Since, the difference between the numerical and experimental values of total loads, separable hydrodynamic loads and ice loads is small; this directly implies that the difference between the numerical and experimental values of inseparable hydrodynamic loads is also small. Thus, we can assert that the algorithm for the calculation of the inseparable hydrodynamic loads by Ice-PPB is reliable, precise and accurate. The inseparable hydrodynamic loads depend on the ice-wake velocity and ice-wake region and it can be inferred that the methods and assumptions used for their calculation are quite accurate. Therefore, no further calibration of any kind is needed as far as the inseparable hydrodynamic loads are concerned.

\section{RESULTS AND CRITICAL ANALYSIS}


Post calibration, the numerical code was used to generate results and study the influence of various parameters on the ice loads. The most relevant parameters that were studied are the advance coefficient, propeller RPM, depth of cut, and ice compressive strength.

\subsection{ADVANCE COEFFICIENT}

The variation of the ice loads with the advance coefficient is shown in Fig 15, demonstrating the effect of propeller-ice interaction on the characteristic curves of a propeller. The total loads on the propeller and its two components (ice contact and hydrodynamic loads) are compared to the reference open-water load curves.
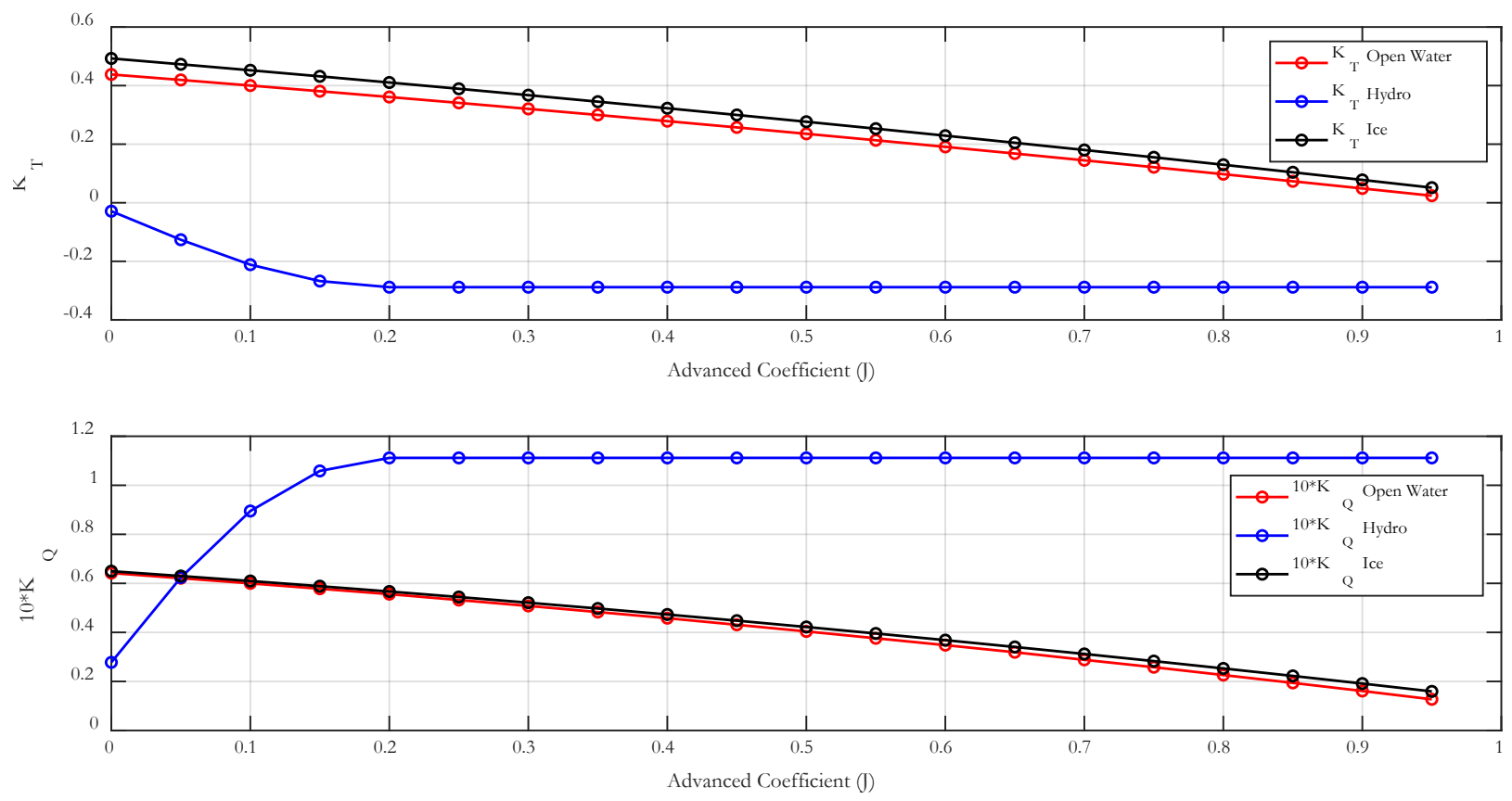

Fig 15 - Variation of KT and KQ with J (From Simulation).

The variation of the total hydrodynamic loads is very similar to the open-water curves. The hydrodynamic loads decrease with the increase in the value of $\mathrm{J}$ due to the decrease in the angle of attack on the propeller blade sections. The difference between the open water loads and the total hydrodynamic loads increases with the increase in the value of $\mathrm{J}$, due to the presence of the inseparable hydrodynamic loads. These loads are a result of the blockage effect of ice, which leads to the formation of the ice wake region, and the influence of this wake field is strengthened at higher J values.

The variation of the ice contact loads shows a different trend. The magnitude (absolute value) of the ice contact loads first increases with $\mathrm{J}$ and then attains a constant value. From the equations (2) - (4) and (8) - (9) it can be seen that for a constant RPM, the magnitude of Cp and Tw due to ice milling is independent of advance velocity and therefore the advance coefficient. The observed trend however, is explained by the shadow effect as the number of shadow panels is dependent on the value of $\mathrm{J}$ as explained before. Furthermore, for the present value of depth of cut, the critical value of $\mathrm{J}$ is 0.2 and therefore, the magnitude of the ice contact loads attains a constant value after $\mathrm{J}=0.2$, as no new shadow panels are selected with the increase in the value of $\mathrm{J}$ beyond 


\section{2 .}

Finally, the curve of the total loads is calculated from the sum of the hydrodynamic loads and the ice loads. In case of torque coefficient $\left(\mathrm{K}_{\mathrm{Q}}\right)$, the total load value first increases as the increase in the ice contact loads is larger in magnitude than the decrease in the hydrodynamic loads. When the ice contact loads attain a constant value, the total loads then decrease due to the progressive decrease in the hydrodynamic loads as J increases. In case of the thrust coefficient $\left(\mathrm{K}_{\mathrm{T}}\right)$, the total load value first decreases rapidly due to the large increase in the magnitude of the ice contact loads acting in the opposite direction as the hydrodynamic thrust, and when the ice loads attain a constant value, the total loads start decreasing slowly with the increase in the value of $\mathrm{J}$ due to the decrease in the hydrodynamic loads.

\subsection{PROPELLER RPM}

The hydrodynamic loads acting on the propeller depend on the advance ratio and thus, at a constant advance velocity, as the RPM of the propeller is increased, the value of $\mathrm{J}$ decreases and with the decrease in the value of $\mathrm{J}$, the hydrodynamic loads increase. Thus, at a given value of advance velocity, an increase in the propeller RPM, increases the hydrodynamic loads.

The situation is totally opposite for the ice contact loads. The ice contact loads are calculated by the empirical formulae as shown in equations (2) - (4) and (8) - (10). From these equations we can see that the increase in the RPM of the propeller leads to the decrease in the value of EFC (due to increase in the strain rate) and thus leads to the decrease in the ice contact loads as shown in Fig 16. This result confirms the usual practice of operating the propellers at high RPM in ice. It is important to point out here that for a given value of $\mathrm{J}$, the change in the propeller RPM does not influence the number of shadow panels, as it is only dependent on the $\mathrm{J}$ value (Eqn. 7). Thus, the change in the ice loads with the change in the RPM is only due to the change in the strain rate. 


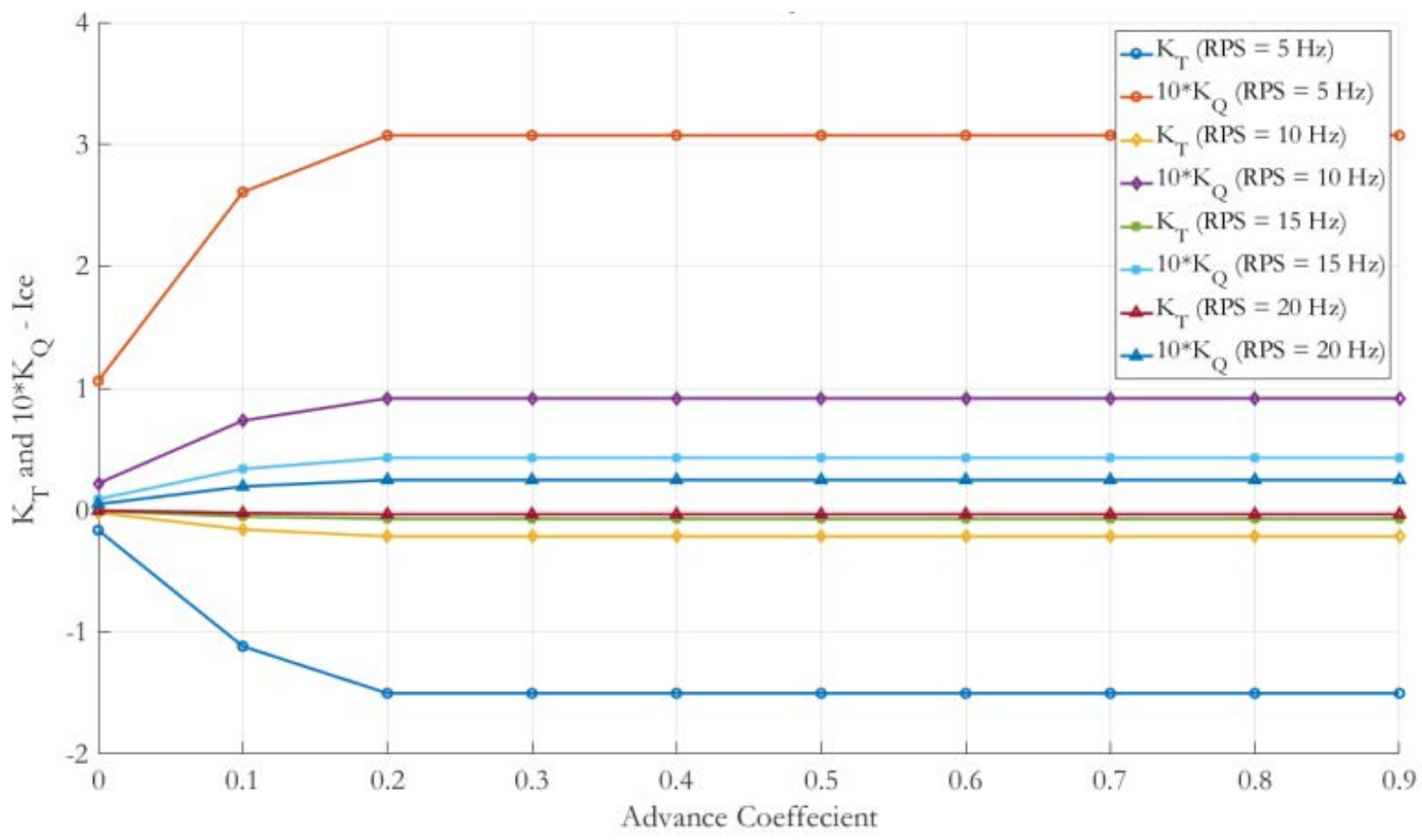

Fig 16 - Variation of Ice Contact Loads with Propeller RPS (From Simulation).

From Fig 16, it can be seen that, the critical value of $\mathrm{J}=0.2$ in all the cases. This is because, the critical $\mathrm{J}$ value is dependent on the depth of cut and is independent of the propeller RPM as explained earlier.

\subsection{DEPTH OF CUT}

The change in the depth of cut influences both the hydrodynamic and ice contact loads. The increase in the depth of cut increases the ice wake region, which in turn increases the inseparable hydrodynamic loads. Since, the contribution of the inseparable hydrodynamic loads to the total hydrodynamic loads is very small, the influence of the depth of cut on the hydrodynamic loads can be considered as negligible.

The dependency of the ice contact loads on the depth of cut is very strong as shown in Fig 17. This is because, with the increase in the depth of cut, more leading edge and shadow panels of the propeller blades come in contact with the ice at a given value of $\mathrm{J}$. 


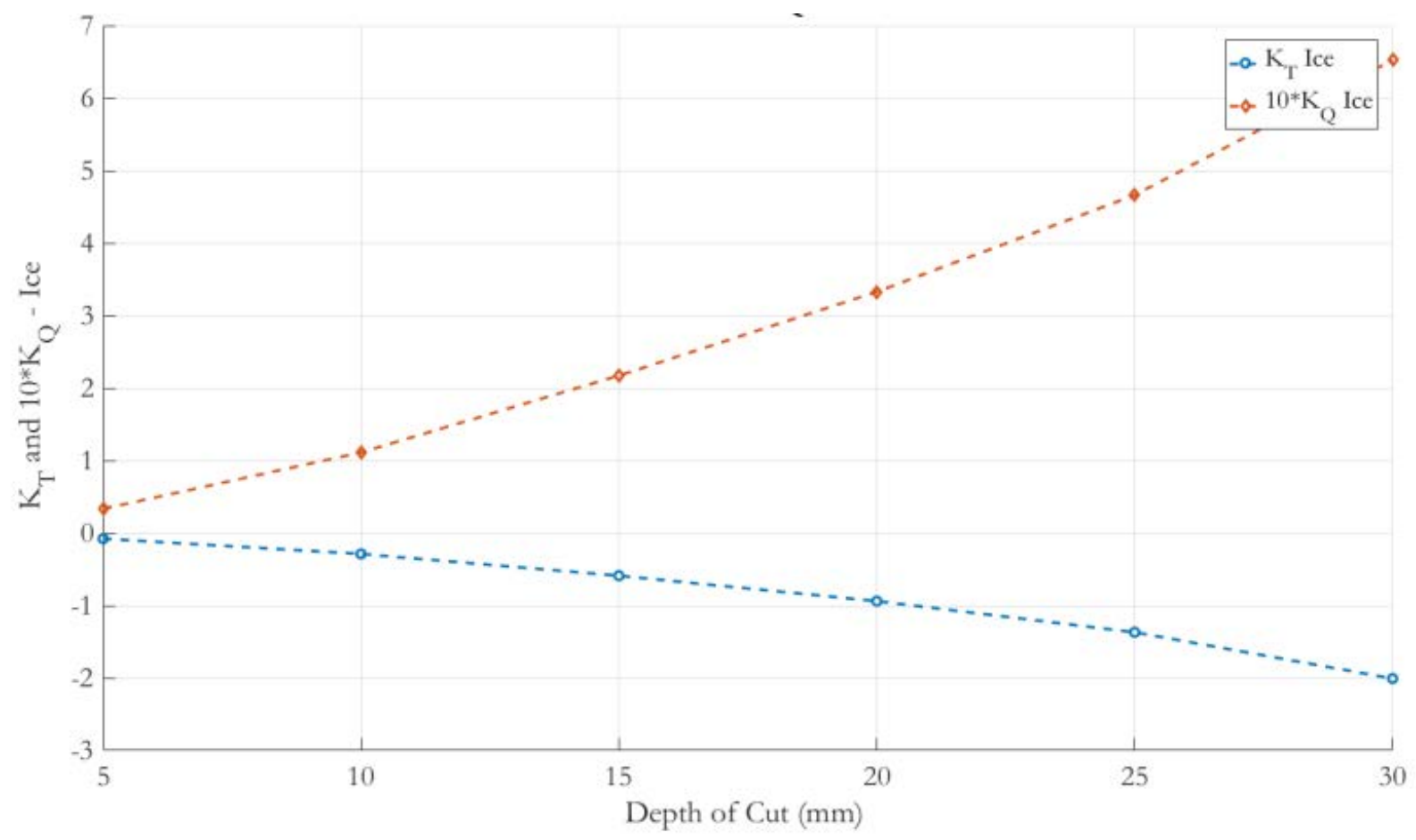

Fig 17 - Variation of Ice Contact Loads with Depth of Cut at a constant J value (From Simulation).

\subsection{ICE COMPRESSIVE STRENGTH}

The ice compressive strength influences only the ice contact loads and the variation of the ice contact loads with the ice compressive strength is parabolic in nature as shown in Fig 18. This is because the relationship between the $C_{p}$ due to ice loads and Ice Compressive strength $\left(S_{\text {ice }}\right)$ is parabolic in nature as seen from equations (2) and (9). 


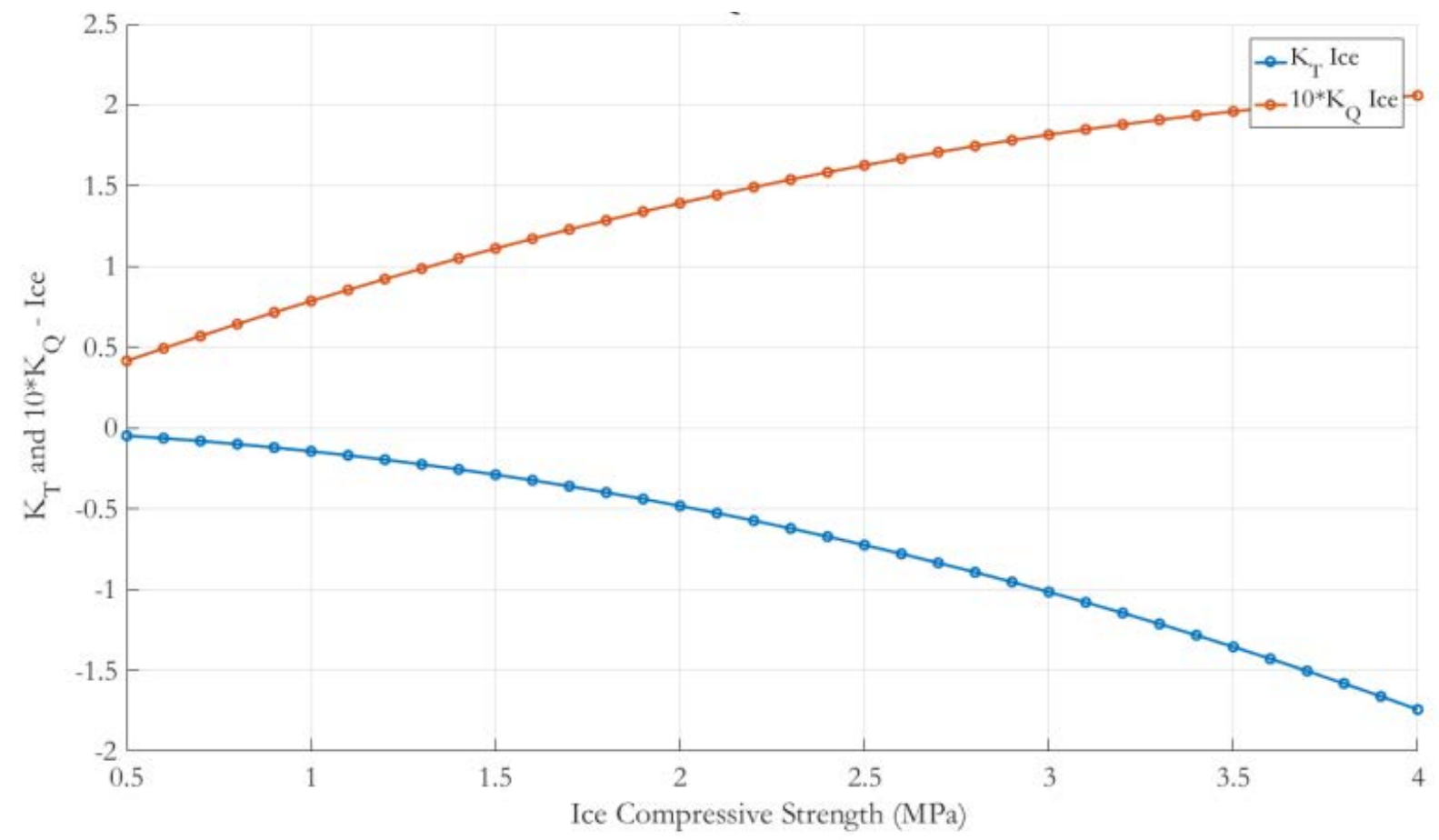

Fig 18- Variation of Ice Contact Loads with Ice Compressive Strength (From Simulation).

\subsection{FINITE ELEMENT ANALYSIS}

After the influence of various parameters on the ice loads is studied, a thorough finite element analysis is done using SAP-4 commercial finite element solver. The purpose of this study is to determine the magnitude and location of the maximum stresses developed on the propeller blades during the ice milling, both under normal and extreme operating conditions. To perform the analysis, the propeller geometry is required as an input. The geometry is then meshed, and the forces and boundary conditions are applied on suitable nodes. The finite element analysis is then performed to calculate the stress distribution across the propeller blade surface.

\subsubsection{Meshing}

The finite element analysis is done on full scale and thus, the full-scale geometry model is used as the input. The full-scale geometry is meshed using a specific technique that generates a mesh with a non-uniform mesh density. The idea here is to have a very fine mesh near the leading edge, the trailing edge, the hub and the tip of the propeller as they are the critical locations with respect to load application and stress concentration. The middle portion of the blade has relatively coarser mesh as shown in Fig 19 below. 


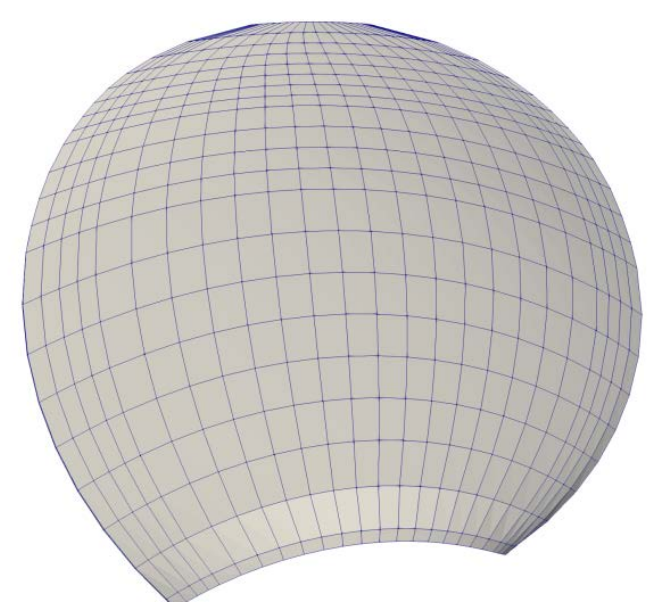

Fig 19 - Meshing of the Propeller Blade Geometry

\subsubsection{Forces and Boundary Conditions}

The next step after the geometry is meshed is to apply the loads and boundary conditions on the nodes. Since, the blade is fixed at the hub and the tip is free to move, it essentially forms a cantilever beam system. Initially, the nodes located at the bottom of the blade that are in contact with the hub, were constrained along all the three directions by setting their displacement to zero, i.e. $u_{x}=u_{y}=u_{z}=0$. This boundary condition lead to unrealistic high stress concentrations and hot spot formation near the root of the blade. The boundary condition were then modified taking into account the root fillet and the connection between the blade root and the hub. To model the fillet, additional nodes of the hub from the pressure as well as the suction side were constrained making the boundary condition more realistic.

The data regarding the forces is obtained from Ice-PPB. However, the Ice-PPB is essentially a panel based code, and the data generated by it consists of panel definitions and the pressure applied on each panel. Moreover, the Ice-PPB generates the data for model scale and the data required by the finite element solver needs to be in full scale. Thus, a pre-processing of the data from Ice-PPB is required in order to apply the correct force vectors on the nodes.

Data Pre-processing: A programming script is developed for data processing that performs the following tasks to translate the panel based data from Ice-PPB into force vectors to be applied on the suitable nodes.

- Convert the pressure applied on each panel from model scale to full scale using the Froude Scaling.

- Convert the pressure applied on each panel to the force acting on the centroid of the panel. The direction of the force on each panel is parallel to the surface normal of the panel.

- Map the coordinates of the corner points of the panels, extrapolate them to full scale, and compare them with the coordinates of the nodes generated from the meshing of propeller geometry.

- Using spline interpolation, transfer the force values from the centroid of panels to the nodes. 
After applying the forces on the nodes, the simulation is run to yield the results. The finite element (FE) solver also calculates the pressure on each element using the values of force applied on the nodes as shown as an example in Fig 20 below.

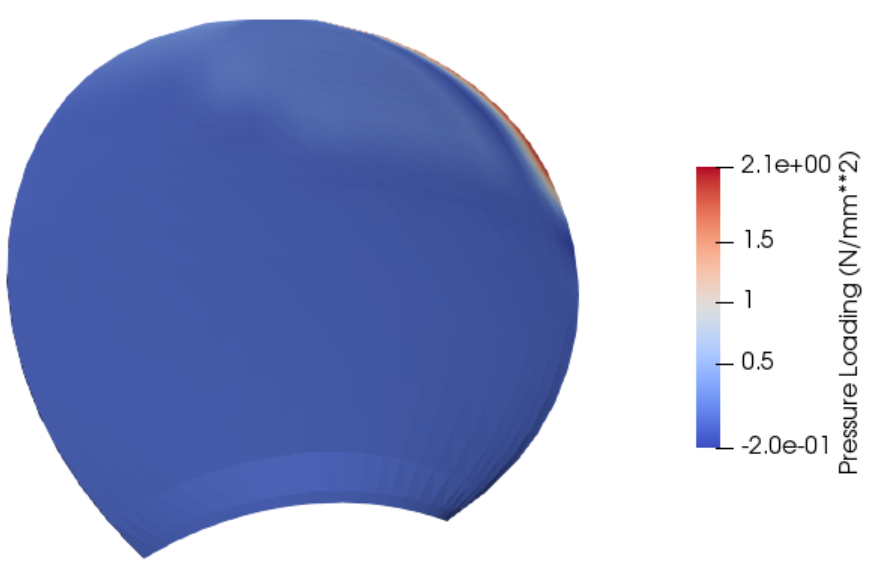

Fig 20 - Pressure Distribution as Calculated by the FE Solver

From Fig 20, it can be seen that the pressure is mainly concentrated along the leading edge, and it is in coherence with the load data from Ice-PPB. The load data from the Ice-PPB is based on the total loads, but the ice loads are much higher in magnitude than the hydrodynamic loads, thereby concentrating the total loads along the leading edge.

\subsubsection{Results}

The stresses developed across the blade surface directly depend on the magnitude of the loads acting on the propeller; higher the loads acting on the blades, higher are the stresses developed. The stresses are calculated using the input parameters of the water milling experiment (Test \#3, Table 2) along with the material properties of Aluminum Bronze as shown in Table 6. These parameters are used as an input in Ice-PPB and are therefore in model scale. During the preprocessing of data from Ice-PPB to FE solver, the data gets converted into full scale as discussed earlier.

Table 6: Input Parameters (Model Scale) and Material Properties (Aluminum Bronze)

\begin{tabular}{|ll|l|}
\hline Parameter & & Value \\
\hline Advance Coefficient & {$[-]$} & 0.015 \\
Propeller RPS & {$[\mathrm{Hz}]$} & 9.0 \\
Ice Compressive Strength & {$[\mathrm{MPa}]$} & 1.03 \\
Depth of Cut & {$[\mathrm{mm}]$} & 27 \\
Young's Modulus & {$[\mathrm{MPa}]$} & $1.18 \times 10^{5}$ \\
Material Density & {$\left[\mathrm{kg}-\mathrm{m}^{-3}\right]$} & 7600 \\
Poisson's Ratio & {$[-]$} & 0.33 \\
Yield Strength & {$[\mathrm{MPa}]$} & 240 \\
\hline
\end{tabular}


The FE solver calculates both the normal and shear stresses along all three axes. Since the propeller is made of Aluminum Bronze which is a ductile material, von Mises yield criterion is used.

The results are shown in Fig 21 and Fig 22 below. The stress is mainly concentrated at the root and the blade tip. The maximum stress near the root of the blade is $10 \mathrm{MPa}$ and the maximum stress developed at the blade tip is about $42 \mathrm{MPa}$. Such a high stress concentration may lead to a local deformation of the blade tip.

This high stress is due to the large value of compressive strength of ice in the model scale experiments. Under normal operating conditions, the ice compressive strength is of the order of $100-120 \mathrm{kPa}$ in model scale.
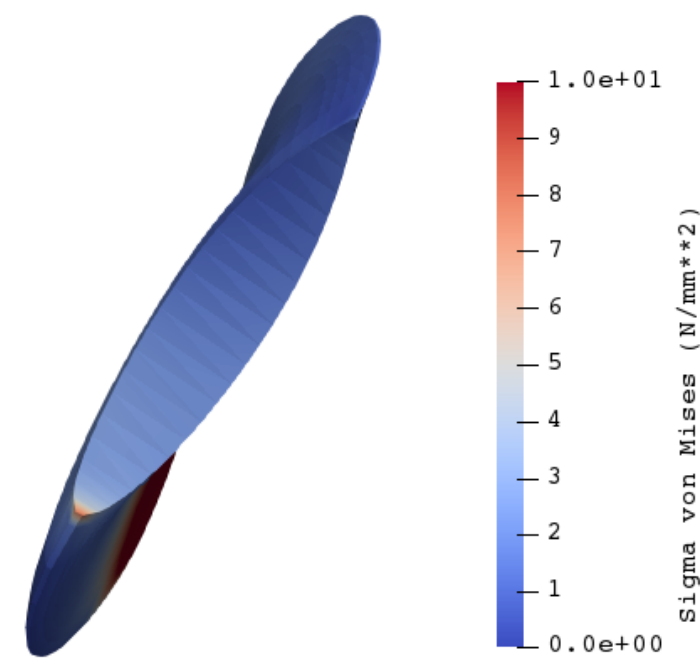

Fig 21 - von Mises Stress Distribution at Root (Test \#3)

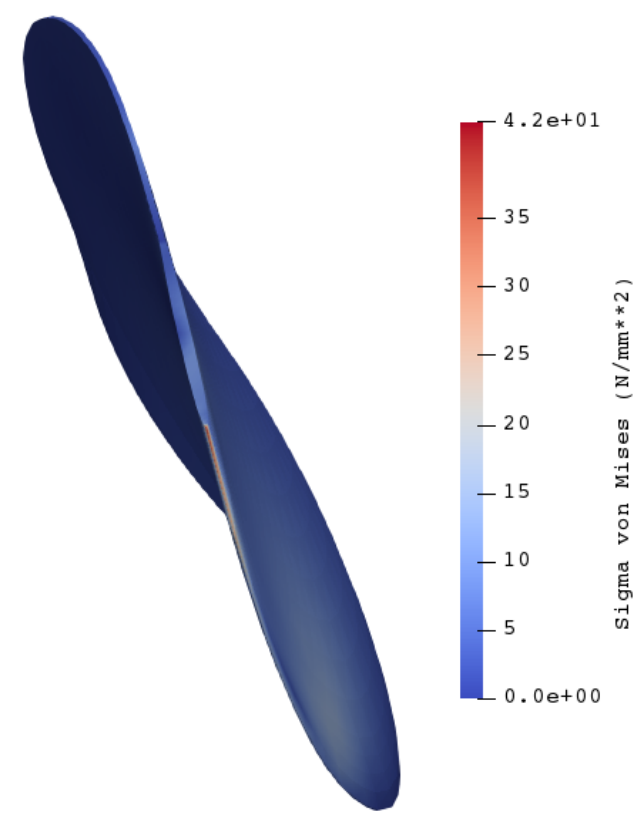

Fig 22 - von Mises Stress Distribution at Blade Tip (Test \#3)

From Fig 21 and Fig 22 above, it can be seen that the maximum stresses are located near the hub and the blade tip. The propeller blade is essentially a cantilever beam, and a large force is applied at the tip of the beam. This results in a very high bending moment at the fixed end, leading to a high stress concentration. As far as the blade tip is concerned, it is subjected to high impact loads leading to higher localized stresses

These results confirm the usual practice of using smaller blades and large hub for ice-class propellers, as larger the hub with respect to the blade, lower is the length of the cantilever, and smaller are the bending stresses developed at the blade-hub interface. Furthermore, the blade thickness in ice - class propellers is also higher in order to avoid the high blade tip stresses.

Furthermore, an extreme operating condition is also simulated, in which the depth of cut is equal to the blade length. This extreme situation arises when the ice is much thicker than the propeller radius. All the parameters are same as Table 6 except the depth of cut, which is changed to 61.5 
$\mathrm{mm}$. The pressure distribution for such case is shown in Fig 23a below. From Fig 23a it can be seen that the entire leading edge of the blade is in contact with ice leading to the generation of large stresses. The maximum stress calculated in this configuration is $52 \mathrm{MPa}$ at the root as shown in Fig 23b.

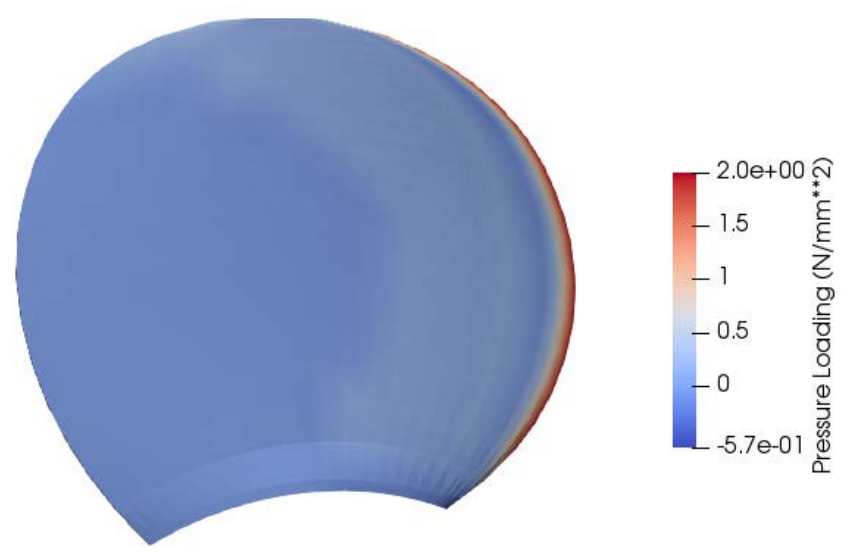

Fig 23a - Pressure Distribution for Extreme Loading Case

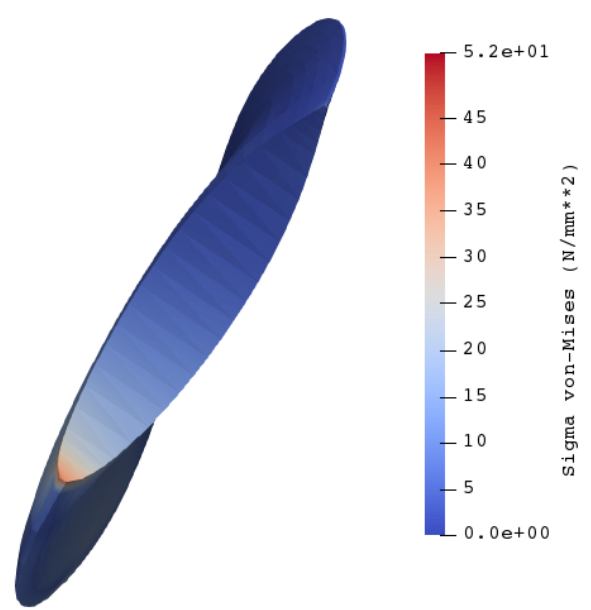

Fig 23b - Stress Distribution for Extreme Loading Case

Influence of Parameters: In addition to the magnitude of the force, the stresses developed also depend upon the location of the force. Using the data values from Table 6, and for a depth of cut of $10 \mathrm{~mm}$, if the location of the force is moved from tip to root, the bending moment developed at the root will reduce and in turn, will reduce the maximum stress developed. The relation between the two is shown in Fig 24 below.

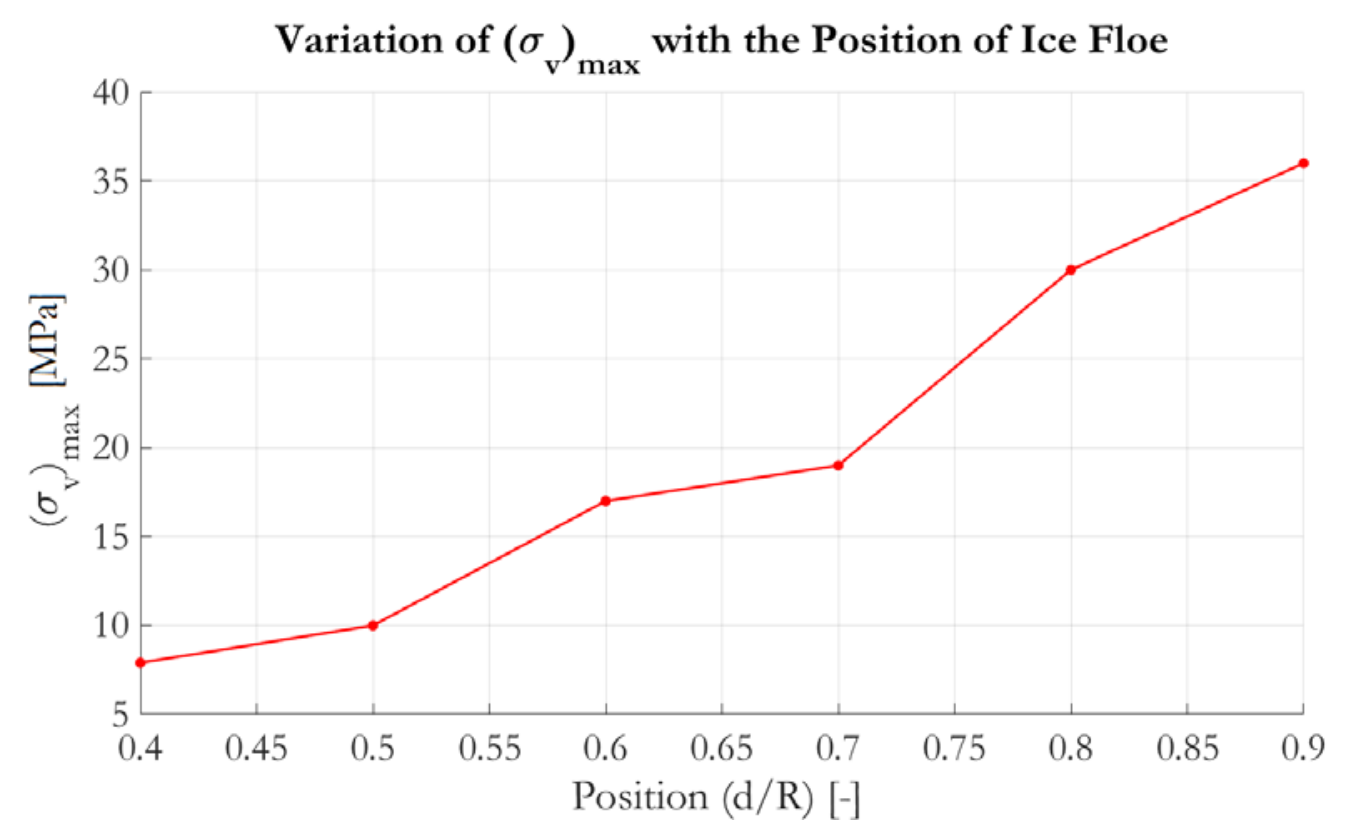

Fig 24 - Variation of Maximum Stress with the Position of Ice Floe 
The relation between the two is not linear as expected, due to geometry of the propeller. As we move from root to tip, the geometry of the blade changes and the contact area of the propeller with ice also changes. The contact area sharply increases after $0.7 \mathrm{R}$ and is reflected in the graph above.

\subsubsection{Validation of FE Results}

The results shown in section 3.5.3 were obtained using the SAP-4 commercial finite element solver. However, in order to ensure the correctness of the results obtained from SAP-4 a comparison was made with results obtained using Ansys solver for the same forces and boundary conditions. The comparison was made for the extreme case shown in Fig 23b. The results from Ansys are shown below in Fig 25.

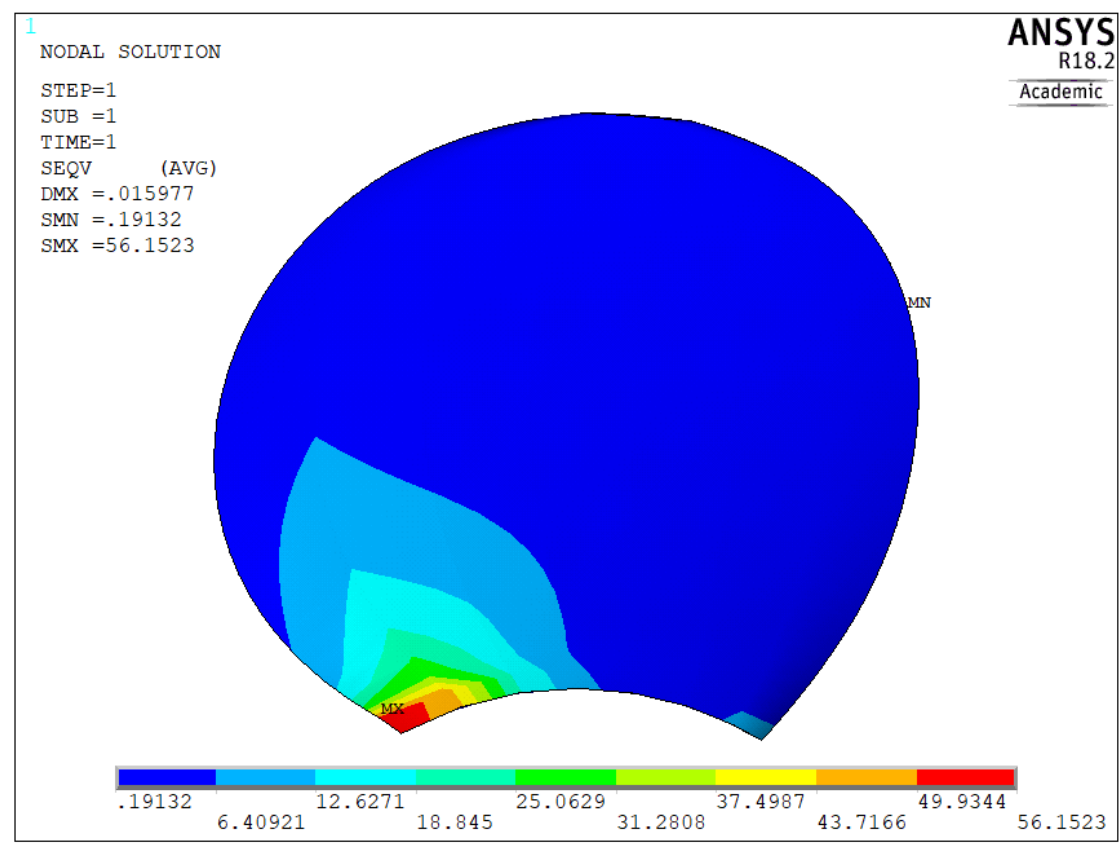

Fig 25 - Stress Distribution at Root for Extreme Loading Case (ANSYS)

The maximum stress calculated by Ansys at the root of the blade is $56.15 \mathrm{MPa}$ and that calculated by SAP-4 is $52 \mathrm{MPa}$ leading to an error of 7.8\%. This shows that the results calculated by SAP-4 are quite reliable.

\section{CONCLUSIONS}

The methodology implemented to calculate the ice loads on a propeller during its interaction with ice was the one used by Wang, $\mathrm{J}(2017 \mathrm{a} / \mathrm{b})$. The total ice loads acting on the propeller was expressed as the linear superposition of the open water (separable) hydrodynamic loads, hydrodynamic loads due to the presence of ice (inseparable) and the ice contact loads. Although the experimental results are in a good agreement with the results of the numerical simulation, it should be noted that the only a very limited number of experiments has been conducted. A consequent test campaign with instrumented propeller is intended to be performed in order to calibrate the numerical tool in a much larger scope.

An interesting point to note is that both Wang, $\mathrm{J}$ (2017a/b) and Bach (2017) had some issues with the noise in the measurement signal rendering some results useless. In order to overcome this 
problem, two improvements were done. The first one was concerning the Ice Feeding Device, which was made structurally robust and sturdier in order to eliminate the vibrations during the milling process. The vibration isolators were also installed at specific positions in order to minimize the signal contamination. Furthermore, the natural frequency of the Feeding Device was kept quite high in order to avoid any issues with resonance at high milling frequencies. The second one was the development of a robust post processing technique that ensured minimum loss of information during the noise attenuation of the signal.

In its actual state, multiple aspects of the numerical tool could be improved. First, a RANSE code to be used instead of a panel based code to determine the hydrodynamic loads. This would not only calculate the hydrodynamic loads with better accuracy but at the same will calculate the exact wake field at the upstream of the propeller due to the presence of the ice as well as the ice feeding device. Additionally, in order to calculate the inseparable hydrodynamic loads with better accuracy, a study on the kinematics of the ice particles is to be done so that depending on their shape and size, the momentum of each ice particle can be determined. As far as ice contact loads are concerned, empirical factors were used to obtain the results. The empirical approach although providing quite accurate results, can be replaced by a more accurate analytical approach. To calculate the ice loads analytically, a detailed study regarding the ice fracture at high indentation speeds needs to be investigated.

Although the finite element analysis was done using a commercial solver, no experiments were conducted to validate the results. The validation of the results was carried out by comparing the results from another commercial solver Ansys. Thus, the new test campaign with the instrumented propeller is also proposed to have strain gauges mounted on the blade surface at critical locations to measure the stresses and strains developed during the ice milling.

\section{Declaration of Conflict of Interest}

The authors certify that they have NO affiliations with or involvement in any organization or entity with any financial interest (such as honoraria; educational grants; participation in speakers' bureaus; membership, employment, consultancies, stock ownership, or other equity interest; and expert testimony or patent-licensing arrangements), or non-financial interest (such as personal or professional relationships, affiliations, knowledge or beliefs) in the subject matter or materials discussed in this manuscript.

\section{ACKNOWLEDGEMENTS}

The authors are grateful the German Federal Ministry of Economics and Technology (BMWi) for financial support of the publication. The authors would also like to thank the national project coordinator PTJ for their administration work.

This paper was partly developed in the frame of the European Master Course in "Integrated Advanced Ship Design” named “EMSHIP” for “European Education in Advanced Ship Design”, Ref.: 159652-1-2009-1-BE-ERA MUNDUS-EMMC.

\section{REFERENCES}


Bach, C. (2017). “An Experimental Method for Model Propeller-Ice Interaction in Air: Concept and First Results", Proceedings of the ASME 2017 36th International Conference on Ocean, Offshore and Arctic Engineering.

Bose, N. (1996). "Ice Blocked Propeller Performance Prediction Using a Panel Method", Transaction of the Royal Institution of Naval Architects, 138.

Bose, N., Veitch, B.J., and Doucet, J.M. (1998). “A Design Approach for Ice Class Propellers”, SNAME Transactions, 106, 185-121.

Cammaert, A. B., Muggeridge, D. B. (1988). “Ice Interaction with Offshore Structures”, Van Nostrand Reinhold, New York, 228.

Ignatjev, M.A. (1964). "Determination of Ice Loads Encountered by Ship Propeller Blades", (translated from Russian), Problems of the Arctic and Antarctic, 15, 41-51.

Jagodkin, V. Ya (1963). “Analytical Determination of the Resistance Moment of a Propeller during its interaction with ice", (translated from Japanese), Problem of the Arctic and Antarctic, 13, 79-88.

Jones, Stephen J. (1997). “Propeller-Ice Interaction”, SNAME Transactions, 105, 399-425.

Khan, A.G., Hisette, Q., Streckwall, H. (2018). "Numerical Investigation of Propeller-Ice Interaction Effects", Proceedings of the 28th International Ocean and Polar Engineering Conference, 2018, Sapporo, Japan.

Norhamo, L., et al. (2009). "Challenges related to propulsor - ice interaction in arctic waters", First International Symposium on Marine Propulsors, Trondheim, Norway.

Okamoto, H. et al. (1981a). "Experimental study on propeller ice interaction for ice breaking merchant ship (1st report, ice load model experiment)", Journal of the Society of Naval Architects of Japan, 1981(149), 100-110.

Okamoto, H. et al. (1981b). "Experimental study on propeller ice interaction for ice breaking merchant ship (2nd report, static load test and FEM analyses)", Journal of the Society of Naval Architects of Japan, 1981(150), 359-370.

Liu, P., Bose, N., and Veitch, B.J. (2015). "Evaluation, design and optimization for strength and integrity of polar class propellers”, Journal of Cold Regions Science and Technology, 113, 31-39.

Polić, D., Æsøy, V., and Ehlers, S. (2016). "Transient simulation of the propulsion machinery system operating in ice - Modeling approach”, Journal of Ocean Engineering, 124, 437-449.

Soininen, H. (1998), “A Propeller-Ice Contact Model”, PhD Thesis, Valtion Teknillinen Tutkimuskeskus (VTT), Espoo Finland.

Streckwall, H. (1998). "Hydrodynamic Analysis of Three Propellers Using a Surface Panel Method for Steady and Unsteady Inflow Conditions", 22nd ITTC Propulsion Committee, Propeller RANS/Panel Method Workshop.

Tsarau, A., Lubbad, R., and Løset, S. (2016). "A numerical model for simulating the effect of propeller flows in ice management”, Journal of Cold Regions Science and Technology, in press, corrected proof

Varma, G.C. (2000). “Ice Loads on the Propellers Under Extreme Operating Conditions”, Master Thesis, Faculty of Engineering and Applied Science, Memorial University of Newfoundland, 


\section{Canada.}

Veitch, Brian J. (1992). "Propeller Ice Interaction”, PhD Thesis, Faculty of Mechanical Engineering, Helsinki University of Technology, Finland.

Veitch, Brian J. (1995). "Predictions of Ice Contact Forces on a Marine Screw Propeller during the Propeller-Ice Cutting Process”, Mechanical Engineering Series, Ship Laboratory, Helsinki University of Technology, Finland, 118.

Wang, J., (2007a). "Prediction of Propeller Performance on a Model Podded Propulsor in Ice (Propeller - Ice Interaction)”, PhD Thesis, Faculty of Engineering and Applied Science, Memorial University of Newfoundland, Canada.

Wang, J., Jones, S. J., Bose, N., Kim, M.C., and Chun, H.H. (2007b). "Ice Loads Acting on a Model Podded Propeller Blade”, Journal of Offshore Mechanics and Arctic Engineering, 129(3), 236-244.

Wind, J. (1984). “The Dimensioning of High Power Propeller Systems for Arctic Icebreakers and Icebreaking Vessels”, International Shipbuilding Progress, 31, 105-117.

Ye, L.W., Wang, C., Chang, X., and Zhang, H.Y. (2017), "Propeller-ice contact modeling with peridynamics, Journal of Ocean Engineering, 139, 54-64. 